Please do not remove this page

RMIT

UNIVERSITY

\title{
Novel atmospheric extinction measurement techniques for aerospace laser system applications
}

Sabatini, Roberto; Richardson, Mark

https://researchrepository.rmit.edu.au/esploro/outputs/9921859608301341/filesAndLinks?institution=61RMIT_INST\&index=null

Sabatini, R., \& Richardson, M. (2013). Novel atmospheric extinction measurement techniques for aerospace laser system applications. Infrared Physics \& Technology, 56, 30-50.

https://doi.org/10.1016/j.infrared.2012.10.002

Document Version: Accepted Manuscript

Published Version: https://doi.org/10.1016/j.infrared.2012.10.002

Repository homepage: https://researchrepository.rmit.edu.au

(C) 2012 Elsevier B.V. All rights reserved.

Downloaded On 2023/04/26 22:05:11 +1000

Please do not remove this page 
Thank you for downloading this document from the RMIT Research Repository.

The RMIT Research Repository is an open access database showcasing the research outputs of RMIT University researchers.

RMIT Research Repository:/http://researchbank.rmit.edu.au/

\section{Citation:}

Sabatini, R and Richardson, M 2013, 'Novel atmospheric extinction measurement techniques for aerospace laser system applications', Infrared Physics \& Technology, vol. 56, pp. 30-50.

See this record in the RMIT Research Repository at:

https://researchbank.rmit.edu.au/view/rmit:23025

Version: Accepted Manuscript

Copyright Statement: (c) 2012 Elsevier B.V. All rights reserved. Creative Commons Attribution-NonCommercial-NoDerivs 3.0 Australia License

Link to Published Version:

http://dx.doi.org/10.1016/j.infrared.2012.10.002 
This is the author pre-publication version. This paper does not include changes and revisions arising from the peer-review and publishing process. The final paper that should be used for all referencing is:

R. Sabatini and M.A. Richardson, "Novel Atmospheric Extinction Measurement Techniques for Aerospace Laser System Applications." Infrared Physics \& Technology, Vol. 56, pp. 3050. January 2013. DOI: 10.1016/j.infrared.2012.10.002.

This paper is available from Elsevier.

\title{
Novel Atmospheric Extinction Measurement Techniques for Aerospace Laser System Applications
}

\author{
Roberto Sabatini†, Mark Richardson† \\ $\dagger$ Cranfield University - Aerospace Engineering Department, Cranfield, Bedfordshire MK43 OAL, United Kingdom \\ †Cranfield University - Defense Academy of the UK, Shrivenham, Swindon SN6 8LA, United Kingdom
}

\begin{abstract}
Novel techniques for laser beam atmospheric extinction measurements, suitable for manned and unmanned aerospace vehicle applications, are presented in this paper. Extinction measurements are essential to support the engineering development and the operational employment of a variety of aerospace electro-optical sensor systems, allowing calculation of the range performance attainable with such systems in current and likely future applications. Such applications include ranging, weaponry, Earth remote sensing and possible planetary exploration missions performed by satellites and unmanned flight vehicles. Unlike traditional LIDAR methods, the proposed techniques are based on measurements of the laser energy (intensity and spatial distribution) incident on target surfaces of known geometric and reflective characteristics, by means of infrared detectors and/or infrared cameras calibrated for radiance. Various laser sources can be employed with wavelengths from the visible to the far infrared portions of the spectrum, allowing for data correlation and extended sensitivity. Errors affecting measurements performed using the proposed methods are discussed in the paper and algorithms are proposed that allow a direct determination of the atmospheric transmittance and spatial characteristics of the laser spot. These algorithms take into account a variety of linear and non-linear propagation effects. Finally, results are presented relative to some experimental activities performed to validate the proposed techniques. Particularly, data are presented relative to both ground and flight trials performed with laser systems operating in the near infrared (NIR) at $\lambda=1064 \mathrm{~nm}$ and $\lambda=1550 \mathrm{~nm}$. This includes ground tests performed with $10 \mathrm{~Hz}$ and $20 \mathrm{KHz}$ PRF NIR laser systems in a large variety of atmospheric conditions, and flight trials performed with a $10 \mathrm{~Hz}$ airborne NIR laser system installed on a TORNADO aircraft, flying up to altitudes of $22,000 \mathrm{ft}$.
\end{abstract}

Key words: Laser Beam Propagation, Laser Extinction Measurement, Aerospace Electro-Optical Sensor Systems, Aerospace Laser Systems.

\section{Nomenclature}

$\begin{array}{ll}A & =\text { pixel area } \\ a, a_{0} & =1 / e \text { beam radius and } 1 / e \text { radius of a collimated Gaussian beam } \\ a_{d}^{2}, a_{j}^{2}, a_{t}^{2} & =\text { contribution to focal spot area due to diffraction, jitter and turbulence } \\ A H & =\text { Absolute humidity }\end{array}$




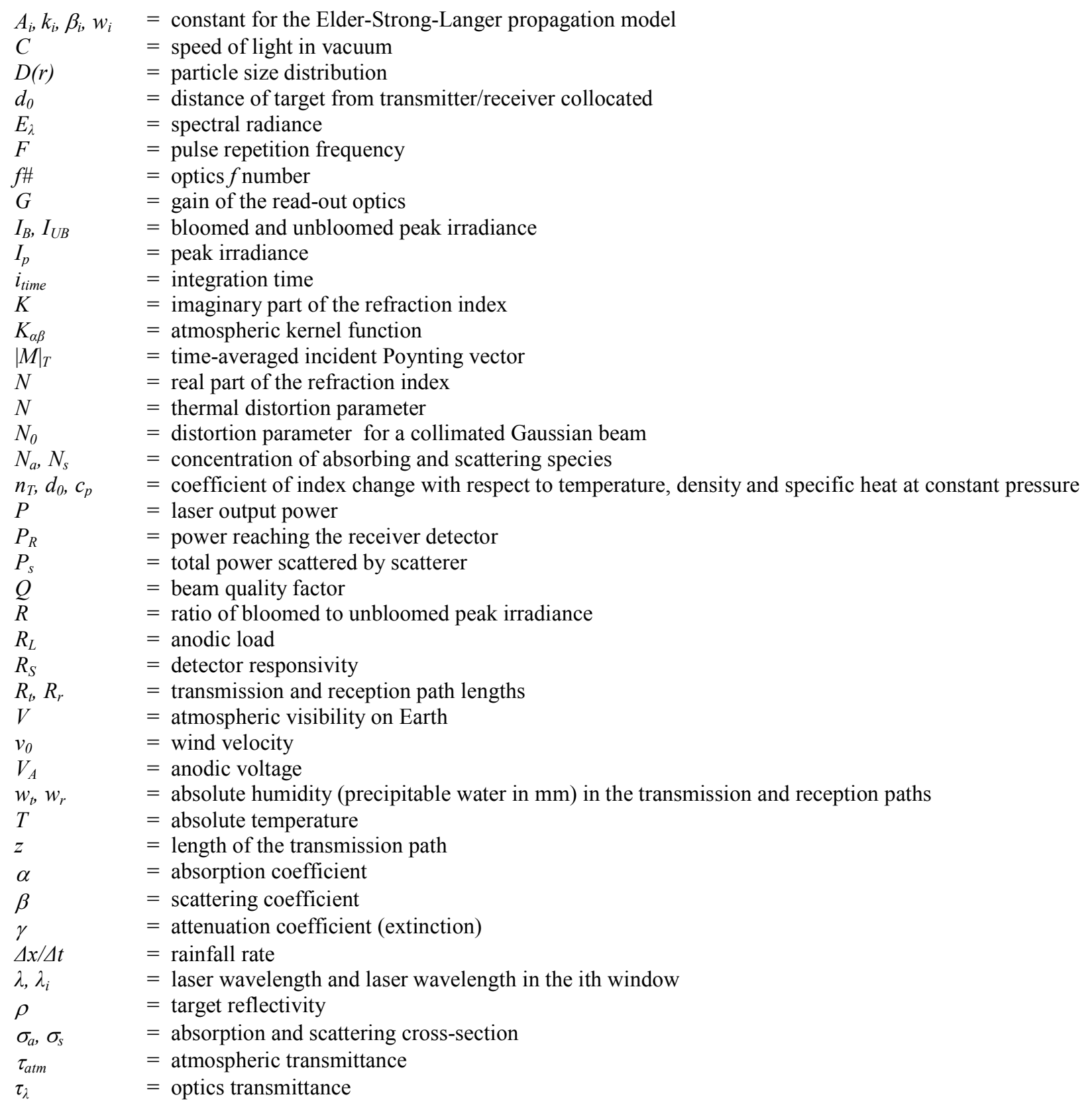

\section{Introduction}

Recent developments in the field of electro-optics have led to innovative laser sensors, systems and advanced processing techniques suitable for aerospace applications. Propagation effects have important consequences for the use of lasers in ranging, weaponry, remote sensing and several other aerospace applications that require transmission of laser through the atmosphere [1]. The laser beam is attenuated as it propagates through the atmosphere, mainly due to absorption and scattering phenomena. In addition, the beam is often broadened, defocused, and may be deflected from its initial propagation direction [2]. The overall attenuation and amount of beam alteration depend on the wavelength of operation, the output power and the characteristics of the atmosphere. When the output power is low, the effects tend to be linear in behaviour. Absorption, scattering, and atmospheric turbulence are examples of linear effects. On the other hand, when the power is sufficiently high, new effects are observed that are characterised by non-linear relationships. Some important non-linear effects are thermal blooming, kinetic cooling, beam trapping, two-photon absorption, bleaching, and atmospheric breakdown, which, incidentally, fixes an upper limit on 
the intensity that can be transmitted. In both cases, the effects can be significant and severely limit the usefulness of the laser beam in aerospace applications. Some features of the interaction of laser beams with the atmosphere are different than those encountered in routine practice with conventional (passive) electro-optical systems. Most of these differences are the result of the interaction of the highly monochromatic laser radiation with the fine structure of the atmosphere. Particularly, molecular absorption and scattering are the dominating attenuation phenomena, both of which are strongly wavelength dependent. Passive electro-optical systems typically operate over bandwidths that are large compared to the width of most molecular absorption lines. As a result, the response of passive systems is integrated over the entire band and the effects the fine structure of the atmosphere are averaged out. These effects, however, are most severe for active laser systems, that typically operate over long ranges and use a naturally occurring atmosphere gas as the laser gain medium. In these cases, in fact, there is an unavoidable coincidence of the laser line with an atmospheric absorption line [3-9]. The atmospheric extinction measurement techniques that we propose here represent valid and relatively inexpensive alternatives to traditional LIDAR systems and are suitable for a variety of platform applications including aircraft, satellites, Unmanned Flight Vehicles (UFV), parachute/gliding vehicles, Roving Surface Vehicles (RSV), or Permanent Surface Installations (PSI). They are based on direct measurement of the laser energy incident on target surfaces of known geometric and reflective characteristics, such as Spectral Reflectance $(\rho)$ and Bidirectional Reflectance Distribution Function (BRDF). A depiction of the possible platform applications is presented in Fig. 1. For vertical/oblique path measurements, the laser source can be located on Satellites, Gliders or UFVs flying in the planet atmosphere at different altitudes (but also manned aircrafts on Earth or their future equivalents on other planets), while for surface layer measurements the laser source could be mounted on RSV or even on PSI turrets at different fixed locations on the planet surface.

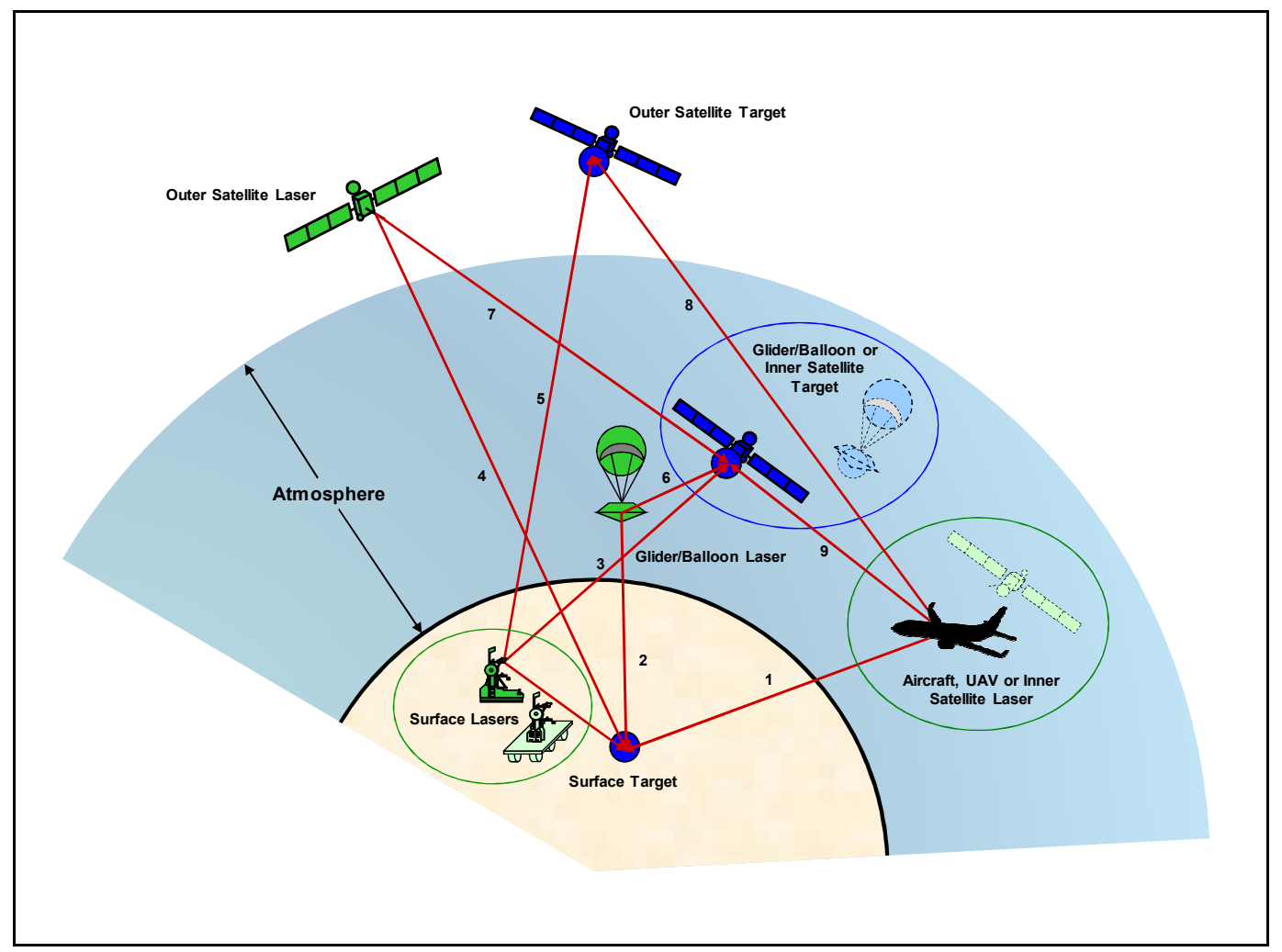

Figure 1. Possible platform applications.

\section{Laser Beam Propagation Overview}

Several research activities have been undertaken for characterizing and modelling linear and non-linear atmospheric propagation effects on laser beams. In this paper, we focus on phenomena affecting the peak irradiance at a distant location from the laser output aperture. 


\subsection{Atmospheric Transmittance}

Attenuation of laser radiation in the atmosphere is described by Beer's law [1]:

$$
\tau_{\text {atm }}=\frac{I(z)}{I_{0}}=e^{-\gamma z}
$$

where $\tau_{\text {atm }}$ is the transmittance, $\gamma$ is the attenuation coefficient (extinction), and $z$ is the length of the transmission path. Since the attenuation coefficient is a function of the molecular and aerosol particle concentrations along the path, Eq. (1) becomes:

$$
\tau_{\text {atm }}=e^{-\int_{0}^{z} \gamma(z) d z}
$$

were the attenuation coefficient is determined by four individual processes: molecular absorption, molecular scattering, aerosol absorption, and aerosol scattering. Therefore:

$$
\gamma=\alpha_{m}+\beta_{m}+\alpha_{a}+\beta_{a}
$$

where $\alpha$ is the absorption coefficient, $\beta$ is the scattering coefficient, and the subscripts $m$ and $a$ designate the molecular and aerosol processes, respectively. Each coefficient in Eq. (3) depends on the wavelength of the laser radiation. We find it convenient at times to discuss absorption and scattering in terms of the absorption and scattering cross sections ( $\sigma_{a}$ and $\sigma_{s}$, respectively) of the individual particles that are involved. Therefore:

$$
\alpha=\sigma_{a} N_{a}
$$

and

$$
\beta=\sigma_{s} N_{s}
$$

where $N_{a}$ and $N_{s}$ are the concentrations of the absorbing and scattering species respectively. In the absence of precipitation, the Earth's atmosphere contains finely dispersed solid and liquid particles (of ice, dust, aromatic and organic material) that vary in size from a cluster of a few molecules to particles of about $20 \mu \mathrm{m}$ in radius. Particles larger than this remain airborne for a short time and are only found close to their sources. Such a colloidal system, in which a gas (in this case, air) is the continuous medium and particles of solid or liquid are dispersed, is known as an aerosol. Aerosol attenuation coefficients depend considerably on the dimensions, chemical composition, and ncentration of aerosol particles. These particles are generally assumed to be homogeneous spheres that are characterized by two parameters: the radius and the index of refraction. In general, the index of refraction is complex. Therefore, we can write:

$$
\tilde{n}=n-i k=n\left(1-i \frac{k}{n}\right)=n(1-i \kappa)
$$

where $n$ and $k$ are the real and imaginary parts and $\kappa=k / n$ is known as the extinction coefficient. In general, both $n$ and $k$ are functions of the frequency of the incident radiation. The imaginary part (which arises from a finite conductivity of the particle) is a measure of the absorption. In fact, $k$ is referred to as the absorption constant. It is related to the absorption coefficient $\alpha$ of Eqs. (3) and (4) by:

$$
\alpha=\frac{4 \pi f k}{c}
$$

where $c$ is the speed of light in a vacuum and $f$ is the frequency of the incident radiation. The scattering coefficient $\beta$ in Eqs. (3) and (5) also depends on the frequency of the incident radiation as well as the index of refraction and radius of the scattering particle. The incident electromagnetic wave, which is assumed to be a plane wave in a given polarization state, produces forced oscillations of the bound and free charges within the sphere. These oscillating charges in turn produce secondary fields internal and external to the sphere. The resulting field at any point is the vector sum of the primary (plane wave) and secondary fields. Once the resultant field has been determined, the scattering cross section $\left(\sigma_{s}\right)$ is obtained from the following relationship: 


$$
\sigma_{s}=\frac{P_{s}}{|M|_{T}}
$$

where $P_{s}$ is the total power scattered by scatterer, and $|M|_{T}$ is the time-averaged incident Poynting vector. In the scattering process there is no loss of energy but only a directional redistribution which may lead to a significant reduction in beam intensity for large path lengths. As is indicated in Table 1, the physical size of the scatterer determines the type of scattering process. Thus, air molecules which are typically several angstrom units in diameter lead to Rayleigh scattering, whereas the aerosols scatter light in accordance with the Mie theory. Furthermore, when the scatterers are relatively large, such as the water droplets found in fog, clouds, rain, or snow, the scattering process is more properly described by diffraction theory.

Table 1. Types of atmospheric scattering.

\begin{tabular}{||l|l||}
\hline Type of Scattering & Size of Scatterer \\
\hline \hline Rayleigh Scattering & Larger than electron but smaller than $\lambda$ \\
\hline Mie Scattering & Comparable in size to $\lambda$ \\
\hline Non-selective Scattering & Much larger than $\lambda$ \\
\hline \hline
\end{tabular}

The atmospheric composition of Earth is largely governed by the by-products of the life that it sustains. Earth's atmosphere consists principally of a roughly 78:20 ratio of nitrogen $\left(\mathrm{N}_{2}\right)$ and oxygen $\left(\mathrm{O}_{2}\right)$, plus substantial water vapour, with a minor proportion of carbon dioxide $\left(\mathrm{CO}_{2}\right)$. Due to human activities, the $\mathrm{CO}_{2}$ concentrations are constantly growing (this has been recognized as a main contributing factor to climate change and global warming). There are also smaller concentrations of hydrogen, and of helium, argon, and other noble gases. Volatile pollutants, including various types of man-made gases and aerosols with largely variable particle size distributions are also present. For the wavelength range of greater interest in laser beam propagation (the visible region to about $15 \mu \mathrm{m}$ ) the principal atmospheric absorbers are the molecules of water, $\mathrm{CO}_{2}$ and ozone. Attenuation occurs because these molecules selectively absorb radiation by changing vibration and rotation energy states. The two gases present in greatest abundance in the Earth's atmosphere, nitrogen and oxygen, are homonuclear, which means that they possess no electric dipole moment and therefore do not exhibit molecular absorption bands. The Earth's atmospheric spectral transmittance $\tau_{(\%)}$ measured over a 1820-m horizontal path at sea-level is shown in Fig. 2. 


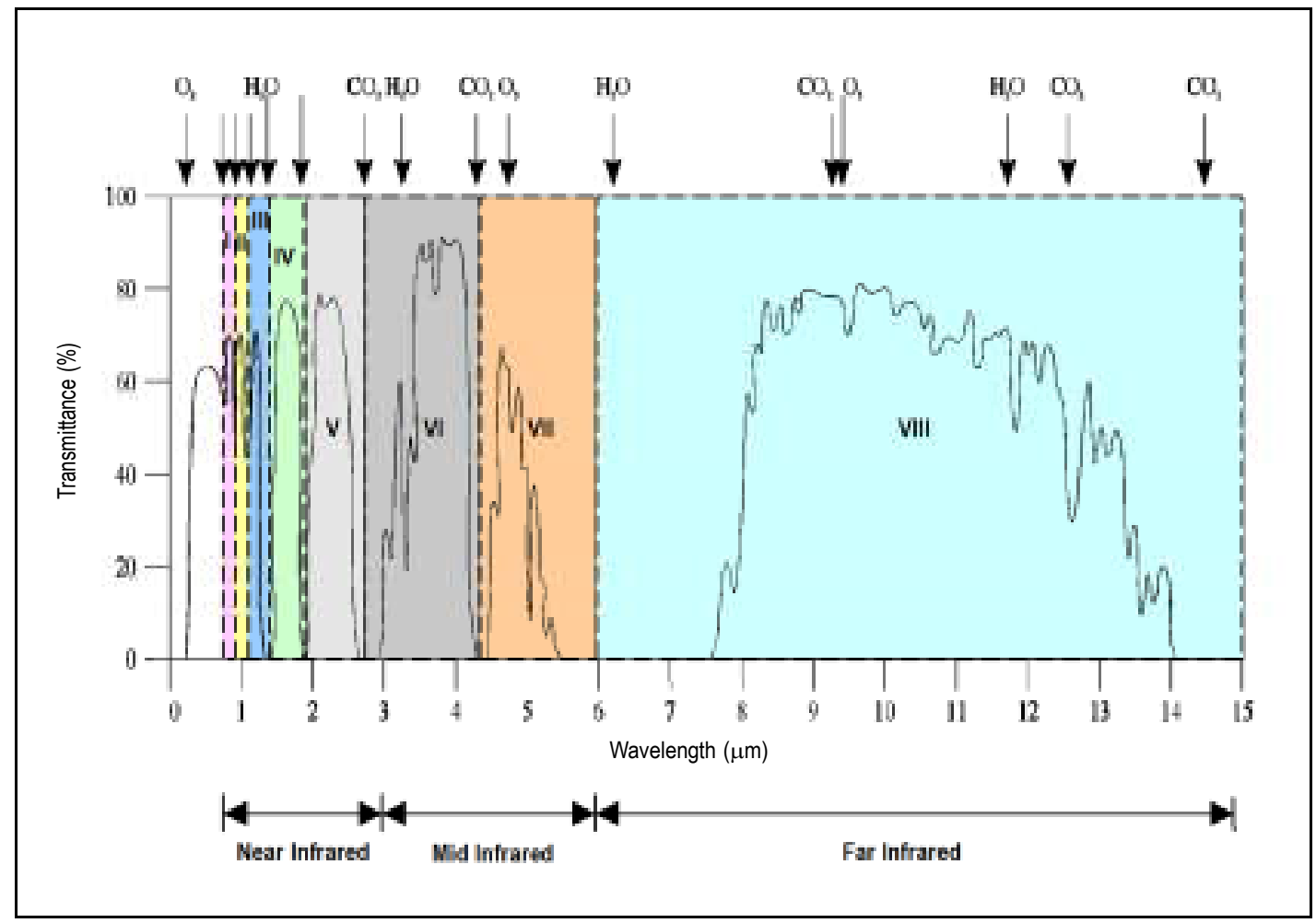

Figure 2. Sea-level transmittance over a $1820 \mathrm{~m}$ horizontal path. Adapted from [2].

The molecule responsible for each absorption band is shown in the upper part of the figure. It is evident that $\mathrm{H}_{2} \mathrm{O}$ and $\mathrm{CO}_{2}$ are by far the most important absorbing molecules. This is also the case for the range of altitudes extending from sea level to about $12 \mathrm{~km}$. Depending on weather conditions, altitude, and geographical location, the concentration of $\mathrm{H}_{2} \mathrm{O}$ varies between $10^{-3}$ and 1 percent (by volume). Normally, the concentration of $\mathrm{CO}_{2}$ varies between 0.03 and 0.04 percent. However, the concentration of $\mathrm{CO}_{2}$ at a local level can reach much higher values due to human activities. Other absorbing molecules found in the atmosphere are methane $\left(\mathrm{CH}_{4}\right)$, with a concentration of around $1.5 \times 10^{-4}$ percent; nitrous oxide $\left(\mathrm{N}_{2} \mathrm{O}\right)$, with a concentration of around $3.5 \times 10^{-5}$ percent; carbon monoxide $(\mathrm{CO})$ with a typical concentration of $2 \times 10^{-5}$ percent; and ozone $\left(\mathrm{O}_{3}\right)$, with a concentration as large as $10^{-3}$ percent at an altitude of around $30 \mathrm{~km}$. The concentration of ozone near sea level is negligible. The wavelength intervals where the transmittance is relatively high are called "atmospheric windows". Obviously, for efficient energy transmission the laser wavelength should fall well within one of these windows. There are a total of eight such windows within the wavelength range from 0.72 to $15.0 \mu \mathrm{m}$. The boundaries are listed in Table 2 . 
Table 2. Wavelength regions of Earth's atmospheric windows.

\begin{tabular}{|c|cc||}
\hline Window Number & \multicolumn{2}{|c|}{ Window Boundaries $(\boldsymbol{\mu m})$} \\
\hline \hline I & 0.72 & 0.94 \\
\hline II & 0.94 & 1.13 \\
\hline III & 1.13 & 1.38 \\
\hline IV & 1.38 & 1.90 \\
\hline V & 1.90 & 2.70 \\
\hline VI & 2.70 & 4.30 \\
\hline VII & 4.30 & 6.00 \\
\hline VIII & 6.00 & 15.0 \\
\hline
\end{tabular}

\subsection{Transmittance Models}

In principle, one could determine the exact composition of the atmosphere over the path of interest and, employing the physics of molecular and aerosol extinction, compute the atmospheric extinction coefficient. Because of the wide variations in weather conditions and sparsity of data on some atmospheric constituents, it is desirable to adopt an engineering approach to atmospheric modelling. The required model must include several weather conditions and shall be validated with laboratory and field data. An empirical approach yielding approximate values of the absorption coefficient, has been suggested by Elder and Strong [3] and modified by Langer [4]. Their approach is particularly useful because it provides a means of relating the atmospheric transmission of the $i^{\text {th }}$ window to the relative humidity (i.e., a readily measurable parameter). The assumption is that variations in the transmission are caused by changes in the water content of the air. Specifically, changes in the concentration of $\mathrm{H}_{2} \mathrm{O}$ cause changes in the absorption, and changes in the size and number of water droplets with humidity cause changes in the scattered component. This is a valid assumption since the other atmospheric constituents have a reasonably constant effect on the transmittance of a given atmospheric window. It is customary to express the number of $\mathrm{H}_{2} \mathrm{O}$ molecules encountered by the beam of light in terms of the number of precipitable millimetres of water in the path. Specifically, the depth of the layer of water that would be formed if all the water molecules along the propagation path were condensed in a container having the same cross-sectional area as the beam is the amount of precipitable water. A cubic meter of air having an absolute humidity of $\rho$ grams per $\mathrm{m}^{3}$ would yield condensed water that cover a $1 \mathrm{~m}^{2}$ area and have a depth of:

$$
w^{\prime}=10^{-3} \rho
$$

Therefore, $w^{\prime}$ is the precipitable water in the path having units of mm per meter of path length. For a path of $z$ meters Eq. (9) becomes:

$$
w=10^{-3} \rho \cdot z
$$

where $w$ is now the total precipitable water in millimetres. The value of $\rho$, the density of water vapour, can be obtained using the following equation [6]:

$$
\rho=1322.8 \cdot \frac{R H}{T} \exp \left[\frac{25.22 \cdot(T-273.16)}{T}-5.31 \cdot \ln \left(\frac{T}{273.16}\right)\right]
$$

where $R H$ is the relative humidity (as a fraction), and $T$ is the absolute temperature $\left({ }^{\circ} \mathrm{K}\right)$. Based on the work done by Elder and Strong [3], two empirical expressions, developed by Langer [4], can be used to calculate the absorptive transmittance $\tau_{a i}$ for the $i^{\text {th }}$ window for any given value of the precipitable water content. These expressions are:

$$
\tau_{a i}=e^{-A_{i} \sqrt{w}}, \text { for } w<w_{i}
$$




$$
\tau_{a i}=k_{i}\left(\frac{w_{i}}{w}\right)^{\beta_{i}}, \text { for } w>w_{i}
$$

where $A_{i}, k_{i}, \beta_{i}$ and $w_{i}$ are constants whose values for each atmospheric window are listed in Table 3 .

Table 3. Constants to be used in Eqs. (12) and (13).

\begin{tabular}{|c|l|l|l|l|}
\hline Window & $\boldsymbol{A}_{\boldsymbol{i}}$ & $\boldsymbol{k}_{\boldsymbol{i}}$ & \multicolumn{1}{|c|}{$\boldsymbol{\beta}_{\boldsymbol{i}}$} & $\boldsymbol{w}_{\boldsymbol{i}}$ \\
\hline I & & & & \\
\hline II & 0.0305 & 0.800 & 0.112 & 54 \\
\hline III & 0.0363 & 0.765 & 0.134 & 54 \\
\hline IV & 0.1303 & 0.830 & 0.093 & 2.0 \\
\hline V & 0.211 & 0.802 & 0.111 & 1.1 \\
\hline VI & 0.373 & 0.814 & 0.1035 & 0.35 \\
\hline VII & 0.598 & 0.827 & 0.095 & 0.26 \\
\hline
\end{tabular}

In summary, Eqs. (12) and (13), together with Eq. (10) and Eq. (11), provide information that can be used to obtain an estimate of the absorptive transmittance $\left(\tau_{a i}\right)$ of laser beams having wavelengths that fall within the various atmospheric windows. The results apply to horizontal paths in the atmosphere near sea-level and for varying relative humidity. To obtain the total atmospheric transmittance we must multiply $\tau_{a i}$ by $\tau_{s i}$ (i.e., the transmittance due to scattering only). Based on rigorous mathematical approaches, the scattering properties of the atmosphere due to the aerosol particles are difficult to quantify, and it is difficult to obtain an analytic expression for the scattering coefficient that will yield accurate values over a wide variety of conditions. However, an empirical relationship that is often used to model the scattering coefficient [5] has the form:

$$
\beta(\lambda)=C_{1} \lambda^{-\delta}+C_{2} \lambda^{-4}
$$

where $C_{1}, C_{2}$, and $\delta$ are constants determined by the aerosol concentration and size distribution, and $\lambda$ is the wavelength of the radiation. The second term accounts for Rayleigh scattering. Since for all wavelengths longer than about $0.3 \mu \mathrm{m}$ the second term is considerably less than the first, it may be neglected. It has been found that $\delta \approx 1.3 \pm 0.3$ produces reasonable results when applied to aerosols with a range of particle sizes. An attempt has also been made to relate $\delta$ and $C_{1}$ to the meteorological range. The apparent contrast $C_{z}$, of a source when viewed at $\lambda=$ $0.55 \mu \mathrm{m}$ from a distance $z$ is by definition:

$$
C_{z}=\frac{R_{s z}-R_{b z}}{R_{b z}}
$$

where $R_{s z}$ and $R_{b z}$ are the apparent radiances of the source and its background as seen from a distance $z$. For $\lambda=0.55 \mu \mathrm{m}$, the distance at which the ratio:

$$
V=\frac{C_{z}}{C_{0}}=\left(\frac{R_{s z}-R_{b z}}{R_{b z}}\right) /\left(\frac{R_{s 0}-R_{b 0}}{R_{b 0}}\right)=0.02
$$

is defined as the meteorological range $V$ (or visual range). It must be observed that this quantity is different from the standard observer visibility $\left(V_{o b s}\right)$. Observer visibility is the greatest distance at which it is just possible to see and identify a target with the unaided eye. In daytime, the object used for $V_{\text {obs }}$ measurements is dark against the horizon sky (e.g., high contrast target), while during night time the target is a moderately intense light source. The International Visibility Code (IVC) is given in Table 4. It is evident that, while the range of values for each category is appropriate for general purposes, it is too broad for scientific applications. 
Table 4. International Visibility Code (IVC).

\begin{tabular}{|c|c|}
\hline Designation & Visibility \\
\hline Dense Fog & $0-50 \mathrm{~m}$ \\
\hline Thick Fog & $50-200 \mathrm{~m}$ \\
\hline Moderate Fog & $200-500 \mathrm{~m}$ \\
\hline Light Fog & $500-1 \mathrm{~km}$ \\
\hline Thin Fog & $1-2 \mathrm{~km}$ \\
\hline Haze & $2-4 \mathrm{~km}$ \\
\hline Light Haze & $4-10 \mathrm{~km}$ \\
\hline Clear & $10-20 \mathrm{~km}$ \\
\hline Very Clear & $20-50 \mathrm{~km}$ \\
\hline Exceptionally Clear & $>50 \mathrm{~km}$ \\
\hline
\end{tabular}

Visibility is a subjective measurement estimated by a trained observer and as such can have large variability associated with the reported value. Variations are created by observers having different threshold contrasts looking at non-ideal targets. Obviously, visibility depends on the aerosol distribution and it is very sensitive to the local meteorological conditions. It is also dependent upon the view angle with respect to the sun. As the sun angle approaches the view angle, forward scattering into the line-of-sight increases and the visibility decreases. Therefore, reports from local weather stations may or may not represent the actual conditions at which the experiment is taking place. Since meteorological range is defined quantitatively using the apparent contrast of a source (or the apparent radiances of the source and its background) as seen from a certain distance, it eliminates the subjective nature of the observer and the distinction between day and night. Unfortunately, carelessness has often resulted in using the term "visibility" when meteorological range is meant. To avoid confusion, the "observer-visibility" $\left(V_{o b s}\right)$ is used in this paper to indicate the estimate. If only $V_{o b s}$ is available, the meteorological range $(V)$ can be approximated by [6]:

$$
V \approx(1.3 \pm 0.3) \cdot V_{o b s}
$$

From Eq. (26), if we assume that the source radiance is much greater than the background radiance (i.e., $R_{s}>>R_{b}$ ) and that the background radiance is constant (i.e., $R_{b o}=R_{b z}$ ), then the transmittance at $\lambda=0.55 \mu \mathrm{m}$ (where absorption is negligible) is given by:

$$
\frac{R_{s v}}{R_{s 0}}=e^{-\beta V}=0.02
$$

Hence, we have:

$$
\ln \left(\frac{R_{s v}}{R_{s 0}}\right)=-\beta V=-3.91
$$

and also:

$$
\beta=\frac{3.91}{V}=C_{1} \lambda^{-\delta}
$$

It follows from Eq. (29) that the constant $C_{l}$ is given by:

$$
C_{1}=\frac{3.91}{V} \cdot 0.55^{\delta}
$$

With this result the transmittance at the centre of the $i^{\text {th }}$ window is: 


$$
\tau_{s i}=e^{-\frac{3.91}{V}\left(\frac{\lambda_{i}}{0.55}\right)^{-\delta} \cdot z}
$$

where $\lambda_{i}$ must be expressed in microns. If, because of haze, the meteorological range is less than $6 \mathrm{~km}$, the exponent $\delta$ is related to the meteorological range by the following empirical formula:

$$
\delta=0.585 \sqrt[3]{V}
$$

where $V$ is in kilometres. When $V \geq 6 \mathrm{~km}$, the exponent $\delta$ can be calculated by:

$$
\delta=0.0057 \cdot V+1.025
$$

For exceptionally good visibility $\delta=1.6$, and for average visibility $\delta \approx 1.3$. In summary, Eq. (32), together with the appropriate value for $\delta$, allows to compute the scattering transmittance at the centre of the $i t h$ window for any propagation path, if the meteorological range $V$ is known. It is important to note here that in general the transmittance will, of course, also be affected by atmospheric absorption, which depending on the relative humidity and temperature may be larger than $\tau_{s i}$.

\subsection{Propagation Through Haze and Precipitation}

Haze refers to the small particles suspended in the air. These particles consist of microscopic salt crystals, very fine dust, and combustion products. Their radii are less than $0.5 \mu \mathrm{m}$. During periods of high humidity, water molecules condense onto these particles, which then increase in size. It is essential that these condensation nuclei be available before condensation can take place. Since salt is quite hygroscopic, it is by far the most important condensation nucleus. Fog occurs when the condensation nuclei grow into water droplets or ice crystals with radii exceeding 0.5 $\mu \mathrm{m}$. Clouds are formed in the same way; the only distinction between fog and clouds is that one touches the ground while the other does not. By convention fog limits the visibility to less than $1 \mathrm{~km}$, whereas in a mist the visibility is greater than $1 \mathrm{~km}$. We know that in the early stages of droplet growth the Mie attenuation factor $K$ depends strongly on the wavelength. When the drop has reached a radius a $\approx 10 \lambda$ the value of $K$ approaches 2 , and the scattering is now independent of wavelength, i.e., it is non-selective. Since most of the fog droplets have radii ranging from 5 to $15 \mu \mathrm{m}$ they are comparable in size to the wavelength of infrared radiation. Consequently the value of the scattering cross section is near its maximum. It follows that the transmission of fogs in either the visible or $I R$ spectral region is poor for any reasonable path length. This of course also applies to clouds. Since haze particles are usually less than $0.5 \mu \mathrm{m}$, we note that for laser beams in the $I R$ spectral region $a / \lambda<<1$ and the scattering is not an important attenuation mechanism. This explains why photographs of distant objects are sometimes made with infraredsensitive film that responds to wavelengths out to about $0.85 \mu \mathrm{m}$. At this wavelength the transmittance of a light haze is about twice that at $0.5 \mu \mathrm{m}$. Raindrops are of course many times larger than the wavelengths of laser beams. As a result there is no wavelength-dependent scattering. The scattering coefficient does, however, depend strongly on the size of the drop. Middleton $[5,6]$ has shown that the scattering coefficient with rain is given by:

$$
\beta_{\text {rain }}=1.25 \cdot 10^{-6} \frac{\Delta x / \Delta t}{a^{3}}
$$

where $\Delta x / \Delta t$ is the rainfall rate in centimetres of depth per second and $a$ is the radius of the drops in centimetres. Rainfall rates for four different rain conditions and the corresponding transmittance (due to scattering only) of a 1.8$\mathrm{km}$ path are shown in Table 5 [2]. These data are useful for order of magnitude estimates. In order to obtain accurate estimates, the concentrations of the different types of rain drops (radius) and the associated rainfall rates should be known. In this case, the scattering coefficient can be calculated as the sum of the partial coefficients associated to the various rain drops. 
Table 5. Transmittance of a $1.8-\mathrm{km}$ path through rain.

\begin{tabular}{|c|c|}
\hline Rainfall (cm/h) & Transmittance (1.8 km path) \\
\hline \hline 0.25 & 0.88 \\
\hline 1.25 & 0.74 \\
\hline 2.5 & 0.65 \\
\hline 10.0 & 0.38 \\
\hline
\end{tabular}

A simpler approach, used in LOWTRAN, gives good approximations of the results obtained with Eq. (25) for most concentrations of different rain particles. Particularly, the scattering coefficient with rain has been empirically related only to the rainfall rate $\Delta x / \Delta t$ (expressed in $\mathrm{mm} /$ hour), as follows [7]:

$$
\beta_{\text {rain }} \approx 0.365 \cdot\left(\frac{\Delta x}{\Delta t}\right)^{0.63}
$$

Table 6 provides representative rainfall rates which can be used in Eqs. (25) and (26), when no direct measurements are available, to obtain order of magnitude estimations of $\beta_{\text {rain }}[8]$.

Table 6. Representative rainfall rates.

\begin{tabular}{|c|c||}
\hline Rain Intensity & Rainfall (mm/hour) \\
\hline \hline Mist & 0.025 \\
\hline Drizzle & 0.25 \\
\hline Light & 1.0 \\
\hline Moderate & 4.0 \\
\hline Heavy & 16 \\
\hline Thundershower & 40 \\
\hline Cloud-burst & 100 \\
\hline
\end{tabular}

In the presence of rain, in addition to the scattering losses calculated with Eq. (25) or (26), there are, of course, losses by absorption along the path, and these must be included in the calculation of the total atmospheric transmittance with rain.

\subsection{Combined ESLM Model}

Combining the equations presented in the above paragraphs, the set of equations presented in Table 7 are obtained, for calculating the one-way atmospheric transmittance $\left(\tau_{\mathrm{atm}}\right)$ in the various conditions. The cases $R_{l}$ and $R_{2}$ in Table 8 are independent of meteorological range $(V)$. Straightforward numerical analysis shows that the $\tau_{\text {atm }}$ estimates obtained with rain using Eqs. (25) and 26), are always less than the corresponding transmittance estimates obtained with Eqs. (22) and (23) with dry-air conditions and $V<6 \mathrm{~km}$, for rainfall rates $\Delta x / \Delta t \geq 1$ (i.e., from light rain to cloud-burst). For double path transmission and in the general case of transmitter and receiver not collocated, the equations in Table 8 have to be modified, taking into account that the total laser path ( $\mathrm{z}$ ) is given by the sum of the 
range transmitter-target $\left(R_{t}\right)$ and target-receiver $\left(R_{r}\right)$. Denoting with the subscripts $\mathrm{t}$ and $\mathrm{r}$ the terms relative to the transmitting and receiving paths respectively, we have that the total atmospheric transmittance $\left(\tau_{\text {tot }}\right)$ is given by:

$$
\tau_{\text {tot }}=\tau_{t} \cdot \tau_{r}
$$

Therefore, in order to account for all possible cases, we have to consider the $2^{3}$ possible combinations referring to dry-air $\left(V \geq 6 \mathrm{~km} \leftrightarrow V<6 \mathrm{~km}, w_{t} \geq w_{i} \leftrightarrow w_{t}<w_{i}\right.$ and $\left.w_{r} \geq w_{i} \leftrightarrow w_{r}<w_{i}\right)$, and the $2^{2}$ combinations relative to rainy conditions $\left(w_{t} \geq w_{i} \leftrightarrow w_{t}<w_{i}\right.$ and $\left.w_{r} \geq w_{i} \leftrightarrow w_{r}<w_{i}\right)$. These combinations are given in the Tables 8 and 9 .

Table 7. One-way transmittance equations.

\begin{tabular}{|c|c|c|c|}
\hline Case & Conditions & Equation & $n^{\circ}$ \\
\hline $\mathbf{A}$ & $\begin{array}{l}\mathrm{V} \geq 6 \mathrm{~km} \\
\mathrm{w}>\mathrm{wi}\end{array}$ & $\tau_{a t m}=k_{i} \cdot\left(\frac{w_{i}}{w_{t}}\right)^{\beta_{i}} e^{-z \cdot \frac{3.91}{V}\left(\frac{\lambda_{i}}{0.55}\right)^{-(0.0057 \cdot V+1.025)}}$ & $(28)$ \\
\hline B & $\begin{array}{l}\mathrm{V} \geq 6 \mathrm{~km} \\
\mathrm{w}<\mathrm{wi}\end{array}$ & $\tau_{\text {atm }}=e^{-z \cdot\left[A_{i} \sqrt{w}+\frac{3.91}{V}\left(\frac{\lambda_{i}}{0.55}\right)^{-(0.0057 \cdot V+1.025)}\right]}$ & (29) \\
\hline $\mathbf{C}$ & $\begin{array}{c}\mathrm{V}<6 \mathrm{~km} \\
\mathrm{w}<\mathrm{wi}\end{array}$ & $\tau_{\text {atm }}=e^{-z \cdot\left[A_{i} \sqrt{w}+\frac{3.91}{V}\left(\frac{\lambda_{i}}{0.55}\right)^{-0.585 \sqrt[3]{V}}\right]}$ & $(30)$ \\
\hline D & $\begin{array}{c}\mathrm{V}<6 \mathrm{~km} \\
\mathrm{w}>\text { wi }\end{array}$ & $\tau_{a t m}=k_{i} \cdot\left(\frac{w_{i}}{w}\right)^{\beta_{i}} \cdot e^{-z \cdot \frac{3.91}{V} \cdot\left(\frac{\lambda_{i}}{0.55}\right)^{-0.585 \sqrt[3]{V}}}$ & (31) \\
\hline $\mathbf{R}_{1}$ & $\begin{array}{l}\text { Rain } \\
\mathrm{w}<\mathrm{w}_{\mathrm{i}}\end{array}$ & $\tau_{a t m}=e^{-A_{i} \sqrt{w}} \cdot e^{-z \cdot\left[0.365 \cdot\left(\frac{\Delta x}{\Delta t}\right)^{0.63}\right]}$ & (32) \\
\hline $\mathbf{R}_{2}$ & $\begin{array}{l}\text { Rain } \\
\text { w>wi }\end{array}$ & $\tau_{\text {atm }}=k_{i}\left(\frac{w_{i}}{w}\right)^{\beta_{i}} \cdot e^{-z \cdot\left[0.365 \cdot\left(\frac{\Delta x}{\Delta t}\right)^{0.63}\right]}$ & (33) \\
\hline
\end{tabular}

The equations presented in the Tables 7, 8 and 9 represent the combined Elder-Strong-Langer-Middleton (ESLM) model, relative to laser beam horizontal-path propagation at sea-level both in dry-air and rain conditions. The validation process of the ESLM model for NIR laser systems was undertaken during this research using experimental data collected in ground trials $(\lambda=1064 \mathrm{~nm}$ and $\lambda=1550 \mathrm{~nm})$. Furthermore, some corrections to be applied with increasing altitudes and with various laser slant-path grazing angles were determined using experimental data collected in flight trials $(\lambda=1064 \mathrm{~nm})$. The results of these activities are described in later sections of this paper. 
Table 8. ESLM-dry equations for transmitter and receiver not collocated.

\begin{tabular}{|c|c|c|c|}
\hline Case & Conditions & Equation & $n^{\circ}$ \\
\hline $\mathbf{E}$ & $\begin{array}{l}\mathbf{V} \geq \mathbf{6} \mathbf{k m} \\
\mathbf{w}_{\mathrm{t}} \geq \mathbf{w}_{\mathrm{i}} \\
\mathbf{w}_{\mathbf{r}} \geq \mathbf{w}_{\mathbf{i}}\end{array}$ & $\tau_{a t m}=k_{i}^{2}\left(\frac{w_{i}^{2}}{w_{t} w_{r}}\right)^{\beta_{i}} e^{-\frac{3.91}{V}\left(\frac{\lambda_{i}}{0.55}\right)^{-(0.0057 \cdot V+1.025)}\left(R_{t}+R_{r}\right)}$ & (34) \\
\hline $\mathbf{F}$ & $\begin{array}{l}\mathbf{V} \geq 6 \mathbf{k m} \\
\mathbf{w}_{\mathrm{t}} \geq \mathbf{w}_{\mathrm{i}} \\
\mathbf{w}_{\mathrm{r}}<\mathbf{w}_{\mathrm{i}}\end{array}$ & $\tau_{\text {atm }}=k_{i}\left(\frac{w_{i}}{w_{t}}\right)^{\beta_{i}} e^{-A_{i} \sqrt{w_{r}}-\frac{3.91}{V}\left(\frac{\lambda_{i}}{0.55}\right)^{-(0.0057 \cdot V+1.025)}\left(R_{t}+R_{r}\right)}$ & $(35)$ \\
\hline $\mathbf{G}$ & $\begin{array}{l}\mathbf{V}<6 \mathbf{k m} \\
\mathbf{w}_{\mathrm{t}} \geq \mathbf{w}_{\mathrm{i}} \\
\mathbf{w}_{\mathrm{r}}<\mathbf{w}_{\mathrm{i}}\end{array}$ & $\tau_{\text {atm }}=k_{i}\left(\frac{w_{i}}{w_{t}}\right)^{\beta_{i}} e^{-A_{i} \sqrt{w_{r}}-\frac{3.91}{V}\left(\frac{\lambda_{i}}{0.55}\right)^{-0.585 \sqrt[3]{V}}\left(R_{t}+R_{r}\right)}$ & (36) \\
\hline $\mathbf{H}$ & $\begin{array}{l}\mathbf{V}<6 \mathbf{k m} \\
\mathbf{w}_{\mathrm{t}} \geq \mathbf{w}_{\mathrm{i}} \\
\mathbf{w}_{\mathrm{r}} \geq \mathbf{w}_{\mathrm{i}}\end{array}$ & $\tau_{\text {atm }}=k_{i}^{2}\left(\frac{w_{i}^{2}}{w_{t} w_{r}}\right)^{\beta_{i}} e^{-\frac{3.91}{V}\left(\frac{\lambda_{i}}{0.55}\right)^{-0.585 \sqrt[3]{V}}}\left(R_{t}+R_{r}\right)$ & (37) \\
\hline I & $\begin{array}{l}\mathbf{V} \geq 6 \mathbf{k m} \\
\mathbf{w}_{\mathrm{t}}<\mathbf{w}_{\mathrm{i}} \\
\mathbf{w}_{\mathrm{r}} \geq \mathbf{w}_{\mathrm{i}}\end{array}$ & $\tau_{a t m}=k_{i}\left(\frac{w_{i}}{w_{r}}\right)^{\beta_{i}} e^{-A_{i} \sqrt{w_{t}}-\frac{3.91}{V}\left(\frac{\lambda_{i}}{0.55}\right)^{-(0.0057 \cdot V+1.025)}\left(R_{t}+R_{r}\right)}$ & (38) \\
\hline $\mathbf{J}$ & $\begin{array}{l}\mathbf{V} \geq 6 \mathbf{k m} \\
\mathbf{w}_{\mathrm{t}}<\mathbf{w}_{\mathrm{i}} \\
\mathbf{w}_{\mathrm{r}}<\mathbf{w}_{\mathrm{i}}\end{array}$ & $\tau_{\text {atm }}=e^{-A_{i} \sqrt{w_{t}}-A_{i} \sqrt{w_{r}}-\frac{3.91}{V}\left(\frac{\lambda_{i}}{0.55}\right)^{-(0.0057 \cdot V+1.025)}\left(R_{t}+R_{r}\right)}$ & (39) \\
\hline $\mathbf{K}$ & $\begin{array}{l}\mathrm{V}<6 \mathbf{k m} \\
\mathbf{w}_{\mathrm{t}}<\mathbf{w}_{\mathrm{i}} \\
\mathrm{w}_{\mathrm{r}}<\mathbf{w}_{\mathrm{i}}\end{array}$ & $\tau_{\text {atm }}=e^{-A_{i} \sqrt{w_{t}}-A_{i} \sqrt{w_{r}}-\frac{3.91}{V}\left(\frac{\lambda_{i}}{0.55}\right)^{-0.585 \sqrt[3]{V}}\left(R_{t}+R_{r}\right)}$ & $(40)$ \\
\hline $\mathbf{L}$ & $\begin{array}{l}\mathrm{V}<6 \mathbf{k m} \\
\mathbf{w}_{\mathrm{t}}<\mathbf{w}_{\mathrm{i}} \\
\mathbf{w}_{\mathrm{r}} \geq \mathbf{w}_{\mathrm{i}}\end{array}$ & $\tau_{\text {atm }}=k_{i}\left(\frac{w_{i}}{w_{r}}\right)^{\beta_{i}} e^{-A_{i} \sqrt{w_{t}}-\frac{3.91}{V}\left(\frac{\lambda_{i}}{0.55}\right)^{-0.58 \sqrt[3]{V}}\left(R_{t}+R_{r}\right)}$ & (41) \\
\hline
\end{tabular}


Table 9. ESLM-rain equations for transmitter and receiver not collocated.

\begin{tabular}{|c|c|c|c|}
\hline Case & Conditions & Equation & $n^{\circ}$ \\
\hline $\mathbf{R}_{\mathbf{3}}$ & $\begin{array}{c}\text { Rain } \\
\mathbf{w}_{\mathrm{t}} \geq \mathbf{w}_{\mathbf{i}} \\
\mathbf{w}_{\mathbf{r}} \geq \mathbf{w}_{\mathbf{i}}\end{array}$ & $\tau_{\text {atm }}=e^{-A_{i}\left(\sqrt{w_{t}}-\sqrt{w_{r}}\right)-0.365\left(\frac{\Delta x}{\Delta t}\right)^{0.63}\left(R_{t}+R_{r}\right)}$ & $(42)$ \\
\hline $\mathbf{R}_{4}$ & $\begin{array}{c}\text { Rain } \\
\mathbf{w}_{\mathbf{t}} \geq \mathbf{w}_{\mathbf{i}} \\
\mathbf{w}_{\mathbf{r}}<\mathbf{w}_{\mathbf{i}}\end{array}$ & $\tau_{a t m}=k_{i}\left(\frac{w_{i}}{w_{t}}\right)^{\beta_{i}} e^{-A_{i} \sqrt{w_{r}}-0.365\left(\frac{\Delta x}{\Delta t}\right)^{0.63}\left(R_{t}+R_{r}\right)}$ & $(43)$ \\
\hline $\mathbf{R}_{\mathbf{5}}$ & $\begin{array}{c}\text { Rain } \\
\mathbf{w}_{\mathbf{t}}<\mathbf{w}_{\mathbf{i}} \\
\mathbf{w}_{\mathbf{r}} \geq \mathbf{w}_{\mathbf{i}}\end{array}$ & $\tau_{\text {atm }}=k_{i}\left(\frac{w_{i}}{w_{r}}\right)^{\beta_{i}} e^{-A_{i} \sqrt{w_{t}}-0.365\left(\frac{\Delta x}{\Delta t}\right)^{0.63}\left(R_{t}+R_{r}\right)}$ & (44) \\
\hline $\mathbf{R}_{\mathbf{6}}$ & $\begin{array}{c}\text { Rain } \\
\mathbf{w}_{\mathrm{t}}<\mathbf{w}_{\mathrm{i}} \\
\mathbf{w}_{\mathbf{r}}<\mathbf{w}_{\mathbf{i}}\end{array}$ & $\tau_{\text {atm }}=e^{-A_{i}\left(\sqrt{w_{t}}-\sqrt{w_{r}}\right)-0.365\left(\frac{\Delta x}{\Delta t}\right)^{0.63}\left(R_{t}+R_{r}\right)}$ & $(45)$ \\
\hline
\end{tabular}

\subsection{Global Model for Atmospheric Propagation}

In this section we describe the global model adopted for calculating the mean peak focal irradiance due to diffraction, random jitter, atmospheric turbulence, and thermal blooming (effects most frequently observed in aerospace laser systems). We assume for convenience a Gaussian beam at the source and an average focused irradiance, which because of beam jitter and turbulence-induced spreading also has a Gaussian distribution. The peak irradiance for such a beam is given by [9]:

$$
I_{p}=\frac{P e^{-\gamma z}}{\pi\left(a_{d}^{2}+a_{j}^{2}+a_{t}^{2}\right)}
$$

where $P$ is the output power, $\gamma$ is the attenuation coefficient, $a$ is the $1 / e$ beam radius, and the subscripts $d, j$, and $t$ refer to diffraction, jitter, and turbulence. The contributions to the focal spot area due to diffraction, jitter, and turbulence are, respectively, given by:

$$
\begin{aligned}
& a_{d}^{2}=\left(Q z \lambda / 2 \pi a_{0}\right)^{2} \\
& a_{j}^{2}=2<\theta_{x}^{2}>z^{2} \\
& a_{t}^{2}=\frac{4 C_{N}^{12 / 5} z^{16 / 5}}{\lambda^{2 / 5}}
\end{aligned}
$$

where $Q$ is the beam quality factor (i.e., the observed beam radius divided by the diffraction- limited radius), and $<\theta_{x}^{2}>$ is the variance of the single axis jitter angle that is assumed to be equal to $<\theta_{y}^{2}>$. In order to account for the thermal blooming effect, Eq. (46) is modified as follows:

$$
I_{p}=\frac{P e^{-\gamma z}}{\pi\left(a_{d}^{2}+a_{j}^{2}+a_{t}^{2}\right)} \times R
$$


where $R$ is the ratio of the bloomed $I_{B}$ to unbloomed $I_{U B}$ peak irradiance. An empirical relationship for $R$ found for propagation in the Earth's atmosphere is the following:

$$
R=\frac{I_{B}}{I_{U B}}=\frac{1}{1+0.0625 N^{2}}
$$

where $N$, the thermal distortion parameter, is a dimensionless quantity that indicates the degree or strength of thermal distortion. Here $N$ is given by:

$$
N=N_{0}\left[\frac{2}{z^{2}} \int_{0}^{z} \frac{a_{0}}{a\left(z^{\prime}\right)} d z^{\prime} \int_{0}^{z^{\prime}} \frac{a_{0}^{2} v_{0} \exp \left(-\gamma z^{\prime \prime}\right)}{a^{2}\left(z^{\prime \prime}\right) v\left(z^{\prime \prime}\right)} d z^{\prime \prime}\right]
$$

where

$$
N_{0}=\frac{-n_{T} \alpha_{m} P z^{2}}{\pi d_{0} v_{0} c_{p} a_{0}^{3}}
$$

is the distortion parameter for a collimated Gaussian beam of $1 / \mathrm{e}$ radius $a_{0}$ and uniform wind velocity $v_{0}$ in the weak attenuation limit $(\gamma z<1)$. The quantities $n_{T}, d_{0}$, and $c_{p}$ are, respectively, the coefficients of index change with respect to temperature, density, and specific heat at constant pressure, and $P$ and $z$ are the laser output power and range, respectively. Eq. (50) is the propagation equation for Gaussian beams. It can be used to calculate the propagation performance of different laser wavelengths. Considering both propagation performances and output power characteristics of state-of-the-art systems, good candidate lasers covering the entire infrared spectrum are listed below:

- $\mathrm{CO}_{2} \rightarrow \lambda=10.591 \mu \mathrm{m}$

- $\mathrm{CO} \rightarrow \lambda=4.9890 \mu \mathrm{m}$

- $\mathrm{DF} \quad \rightarrow \lambda=3.8007 \mu \mathrm{m}$

- $\mathrm{HF} \rightarrow \lambda=2.9573 \mu \mathrm{m}$

- Er:Fiber $\rightarrow \lambda=1.5500 \mu \mathrm{m}$

- Nd:YAG $\rightarrow \lambda=1.0640 \mu \mathrm{m}$

$-\mathrm{Ar} \rightarrow \lambda=0.5145 \mu \mathrm{m}$

$-\mathrm{N}_{2} \rightarrow \lambda=0.3371 \mu \mathrm{m}$

In general, for the mid to far-IR lasers (e.g., $\mathrm{CO}_{2}, \mathrm{CO}$ and DF) the peak irradiance increases with decreasing wavelength in clear and moderate turbulence conditions. For the near to mid-IR lasers (eg., HF, Ar, and Nd:YAG lasers), the peak irradiance is reduced significantly by aerosol scattering and turbulence. It is interesting to note that for the $\mathrm{CO}_{2}$ wavelength, which is dominated by thermal blooming due to stronger molecular absorption, the peak irradiance is relatively insensitive to both turbulence and aerosol effects. At the shorter wavelengths the effects of turbulence and aerosol attenuation produce wide variations in the peak irradiance. The importance of both aerosol scattering and turbulence effects clearly increases at the shorter wavelengths (eg., Ar, $\mathrm{N}_{2}$, Er:Fiber and Nd:YAG lasers). In most cases, the near to mid-IR regions offer the best overall transmission characteristics; in particular, the 3.8- $\mu \mathrm{m}$ DF wavelength is optimum for varying aerosol and turbulence conditions. In summary, the propagation of high-power laser beams through the atmosphere is affected by a host of optical phenomena. For CW beams the most significant phenomena are absorption and scattering by molecules and aerosols, as well as atmospheric turbulence and thermal blooming. In general, thermal blooming tends to dominate the longer wavelengths (5-10 $\mu \mathrm{m}$ ), while aerosol and turbulence effects are more important at the shorter wavelengths and result in larger variations in peak irradiance in the focal plane as atmospheric conditions change. Some of these effects can be overcome by using laser pulses rather than $\mathrm{CW}$ beams and/or adaptive optical techniques.

\section{Extinction Measurement Techniques}

We propose various methods for accurate Laser Extinction Measurement (LEM) that use combinations of different pulsed laser sources, passive infrared imaging systems and direct detection electro-optics systems. The proposed methods are suitable for both Earth remote sensing missions and likely future planetary exploration missions performed by using Satellites, Unmanned Flight Vehicles (UFV), Gliders/Parachutes/Balloons (GPB), Roving Surface Vehicles (RSV), or Permanent Surface Installations (PSI). For vertical/oblique paths sounding, the laser 
source can be located on Satellites (GEO, MEO and LEO) or UFV flying in the planet atmosphere at different altitudes (but also manned aircrafts on Earth or their future equivalents on other planets), while for surface layer measurements the laser source could be mounted on RSV or even on PSI turrets at different fixed locations on the planet surface. All proposed methods offer relative advantages and limitations in different scenarios.

\subsection{LEM-1 Method}

The first method for atmospheric extinction measurements (LEM-1) is depicted in Fig. 3. In this case, the pulse laser energy (transmitted from an aircraft, satellite, UFV, etc.) incident on a reference target surface of known geometric and reflective characteristics ( $\rho, \mathrm{BRDF}$, inclination, etc.), is measured by using NIR cameras with associated image processing software and incorporating appropriate algorithms to perform radiance measurements in the focal plane. Based on the LEM-1 method, two Energy Measurement Techniques (EMT) were developed for non-calibrated (EMT-1) and calibrated (EMT-2) NIR cameras. For the case of non-calibrated IR cameras (EMT-1), the reference target has to be instrumented with suitable IR detectors (e.g., Pyroelectric Probes - PEPs) with associated optics.

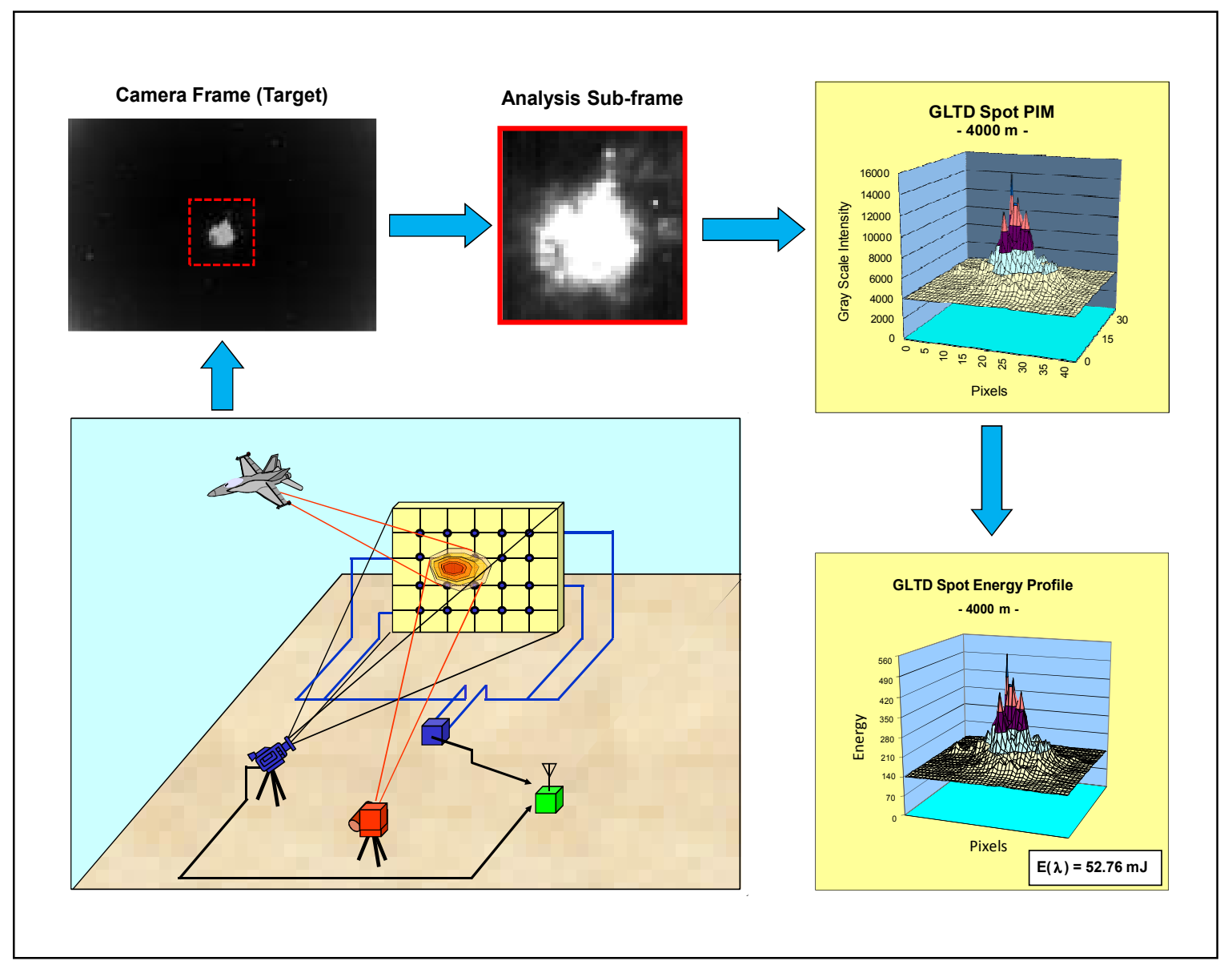

Figure 3. LTM-B Method.

The layout of the instrumented target used for the LEM-1 ground and flight trials is shown in Fig. 4. 


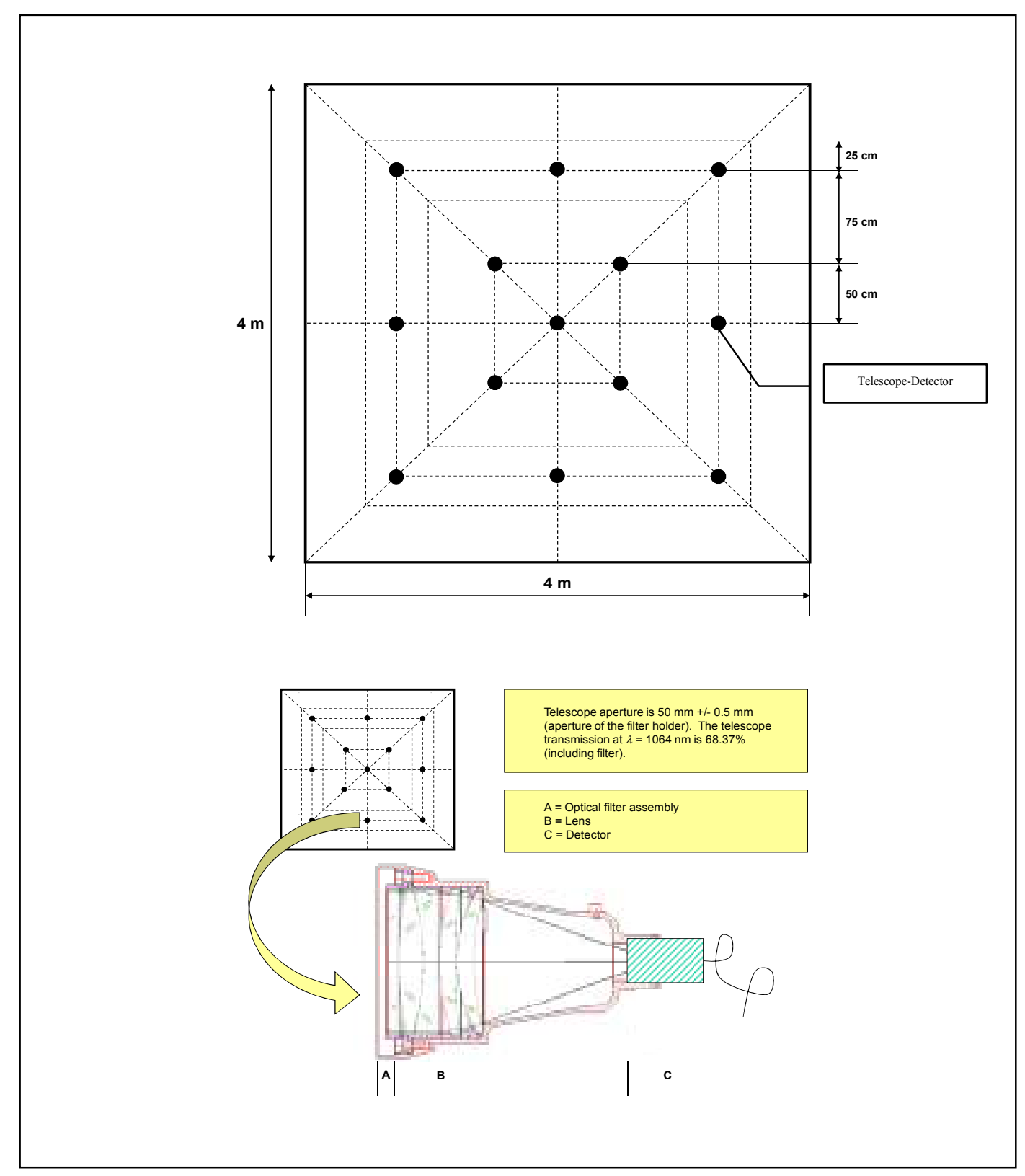

Figure 4. Target layout for LMT-B non-calibrated (EMT-1).

As an alternative to using instrumented targets (EMT-1), the IR cameras were also calibrated to employ EMT-2. Particularly, with reference to Fig. 5, the following instrumentation setup was used for the NIR camera calibration:

- PHOENIX NIR Camera (1);

- Data Acquisition System (2);

- NIR Laser (3);

- NIR Attenuation Filters (4);

- Beam Steering Optics (5);

- Integrating Sphere (6). 
IR cameras employing photo-detectors are characterized by an output signal proportional to the incident IR energy. Particularly, in an IR camera employing a two-dimensional sensor matrix (i.e., Focal Plane Array - FPA) this is true for every single pixel. Therefore, from the numeric information associated to the image (i.e., Grey-scale Pixel Intensity Matrix - GPIM) it is possible to reconstruct the two-dimensional map of the energy irradiated by a target within the scene observed by the IR camera (integrated radiance in the camera spectral band). In the IR camera, the FPA analog signals are processed by the read-out electronic circuits, producing a digital output of the image (typically 12-bit Analog Digital Unit - ADU). Therefore, constructing a calibration curve for the Radiant Intensities $\left(\mathrm{W} / \mathrm{cm}^{2} \mathrm{sr}\right)$ associated to the ADU Grey-scale values, and using dedicated image analysis software, it is possible to obtain the image Energy Pixel Intensity Matrix (EPIM) giving the energy associated to each pixel in the IR camera image. The linearity of the photo-detector response allows accurate measurements in the camera dynamic range, with only a limited number of calibration data points. Furthermore, IR cameras featuring a variable integration time (selectable by the operator), give the opportunity of performing measurements in a linear regime within a wide interval of integrated radiance values, thus obtaining reliable measurements. However, due to Non-Uniformity Correction (NUC), the calibration needs to be conducted on a pixel-by-pixel basis and, for many IR cameras, needs to be repeated regularly.

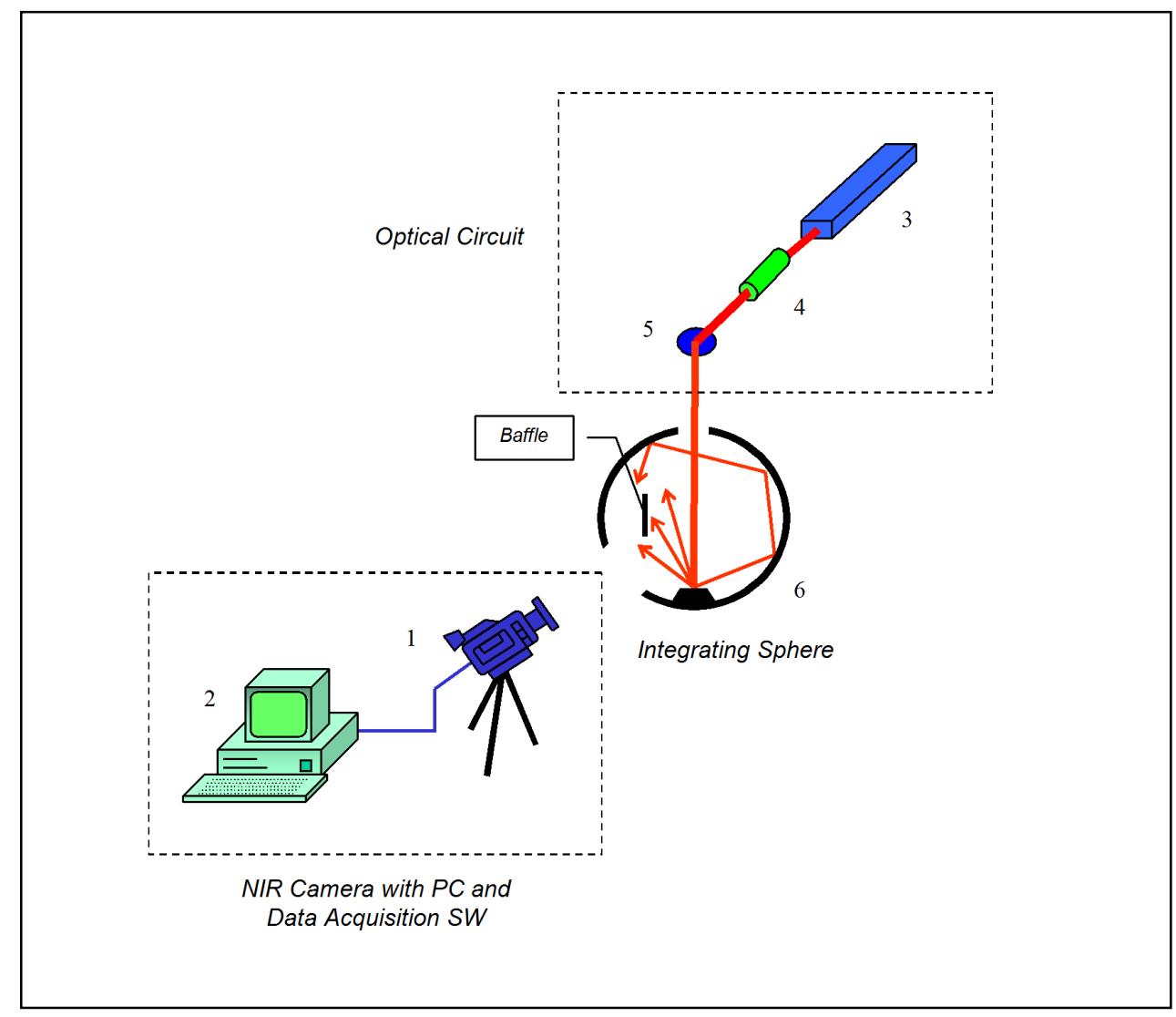

Figure 5. NIR camera calibration procedure (EMT-2).

Calibration allows determination of the ADU/Integrated Radiance Response Function (AIRF). The inverse of the AIRF is used by the image analysis software tool in order to obtain, directly as an image attribute, the values of integrated energy in the spectral band of the camera. For a photo-detector, the response of a single pixel in terms of ADU is:

$$
\mathrm{ADU}_{\mathrm{i}, \mathrm{j}} \propto \frac{\mathrm{A}}{4 \cdot \mathrm{f} \#^{2}+1} \cdot \mathrm{g} \cdot \mathrm{i}_{\text {time }} \cdot \int_{\lambda_{1}}^{\lambda_{2}} \tau_{\lambda} \eta \cdot \mathrm{E}_{\lambda} \mathrm{d} \lambda
$$


where $\lambda$ is wavelength, $\lambda_{1}$ and $\lambda_{2}$ are the limits of the camera spectral band (filtered), $\eta$ is the detector quantum efficiency (whose spectral distribution is typically constant), $E_{\lambda}$ is the spectral radiance, $\tau_{\lambda}$ is the optics transmittance, $A$ is the pixel area, $g$ is the gain of the read-out electronics, $f \#$ is the f-number of the optics and $i_{\text {time }}$ is the camera integration time. Therefore, the experimental parameters to be controlled during the calibration procedure are the integration time, the optics f-number and other settings of the NIR camera (e.g., the gain of the read-out electronics which may be selected by the operator). Fixing these parameters for a certain interval of integral radiance, it is possible to determine the AIRF of the camera by using an extended reference source. The function (calibration curve) so obtained, valid for the specific setup of the camera previously defined, is then used to determine the values of integral radiance to be used for reconstructing the radiant intensity map of the target. As an example, the spectral response (determined experimentally) of an NIR camera InGaAs sensor is shown in Fig. 6.

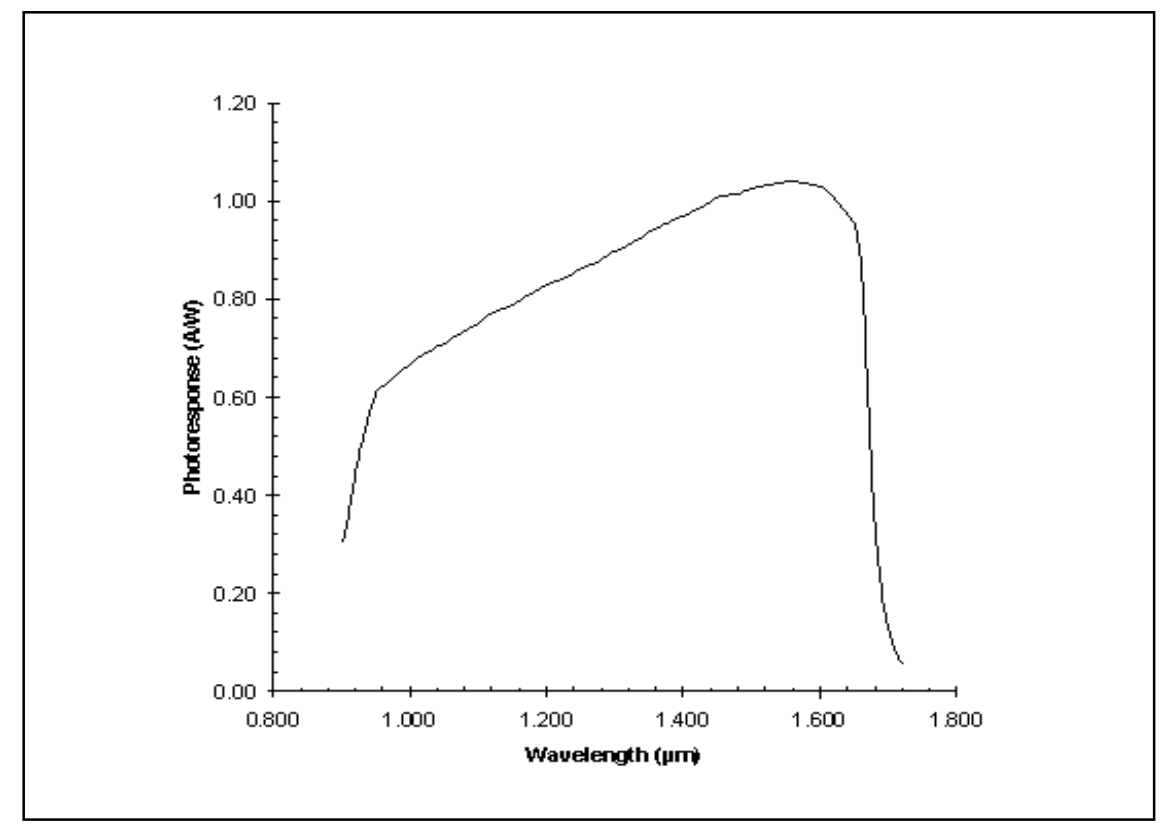

Figure 6. Spectral response of an InGaAs FPA.

The curve shows that the sensor output is a value of radiance integrated in the band $0.9-1.6 \mu \mathrm{m}$. This implies that, in order to perform measurements of the energy reflected by a target (with known reflectance characteristics) illuminated by a laser, it is necessary to reduce the spectral response of the camera by using a narrow band filter (centred on the laser wavelength), in order to mitigate the contributions of the background. The use of such a filter allows, using the same camera setup, accurate measurements of laser energy, independently from the ambient illumination, both in day and night conditions.

\subsection{LEM-2 Method}

The second method proposed (LEM-2) is illustrated in Fig. 3. This technique, unlike LEM-1, employs a modified Laser Range Finder (LRF) system, properly instrumented to measure the transmitted laser power and the receiver detector output voltage. The LRF laser beam with output power $\left(P_{01}\right)$ is aimed at a target of known spectral reflectance $(\rho)$ and diffuse BRDF, located at a known distance $\left(d_{1}\right)$ from the laser source. The reflected laser radiation is measured at the LRF location as a detector output voltage $\left(V_{l}\right)$. Successively, the laser (with output $P_{02}$ $\neq P_{01}$ in general, due to output power fluctuations) is fired towards a second target of identical characteristics located at a longer distance $\left(d_{2}\right)$ and the detector output voltage $\left(V_{2}\right)$ is measured again. Using these data, atmospheric extinction $(\gamma)$ can be computed using the algorithms described here. This technique is useful for high PRF laser systems (PRF exceeding the NIR camera frame rate) and was also used in our research as an additional control technique for LEM-1/EMT-1 and LEM-1/EMT-2. 


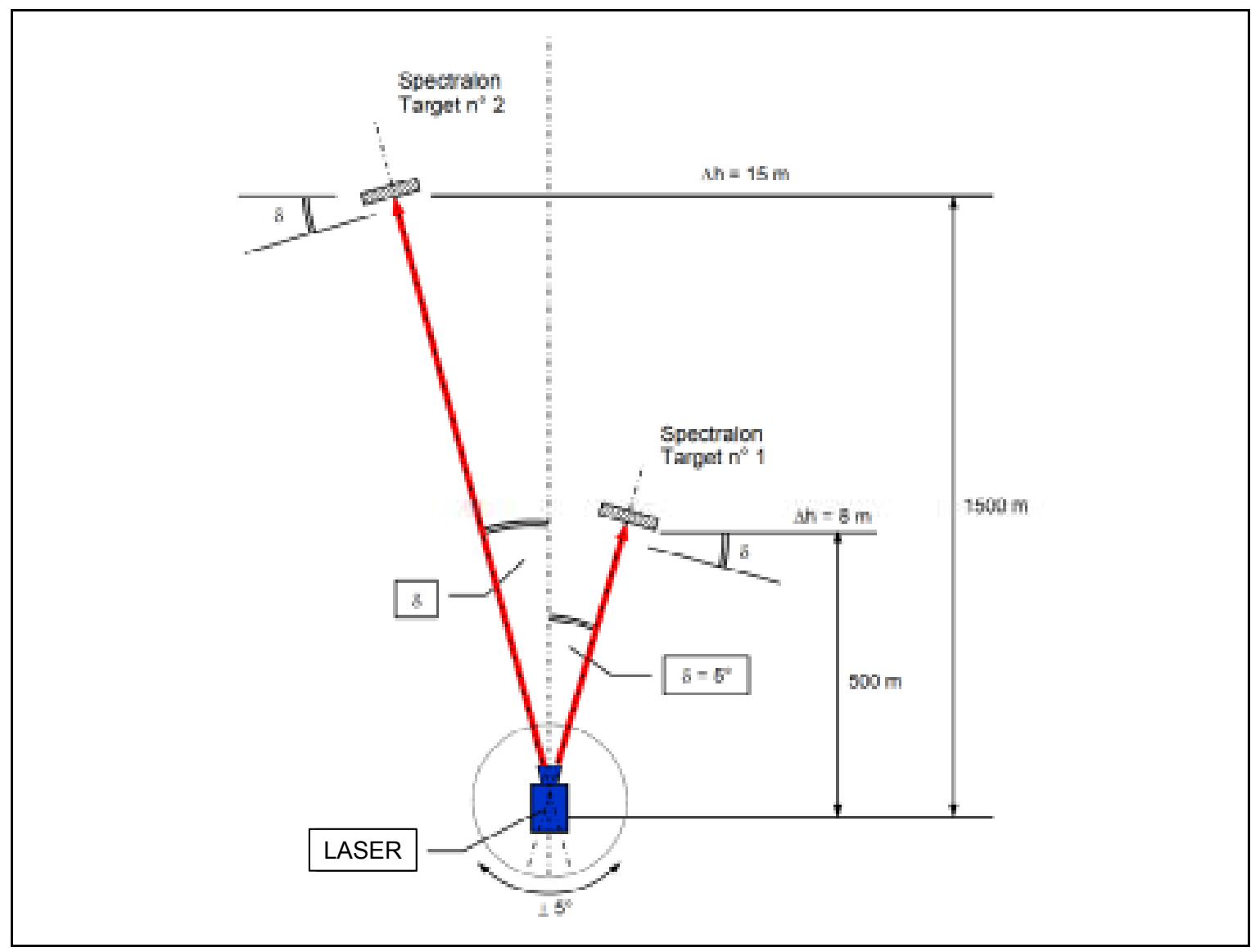

Figure 3. LAS-A Method.

In general, the function describing the anodic voltage at the receiver can be expressed in the form:

$$
V_{A}=R_{L} \cdot R_{S} \cdot P
$$

where $V$ is the anodic voltage, $R_{L}$ is the anodic load $(\Omega), R_{S}$ is the detector responsivity $(A / W)$, and $P_{R}$ is the power reaching the receiver detector $(W)$. Assuming an extended target, the power at the detector can be expressed as:

$$
P=K_{S Y S} \cdot \rho \cdot \frac{1}{d_{0}{ }^{2}} \cdot e^{-2 \gamma d_{0}}
$$

where $\rho$ is the target reflectivity, $d_{0}$ is the distance of the target from the transmitter/receiver, and $\gamma$ is the extinction coefficient. $K_{S Y S}$ is a constant which accounts for all relevant transmitter/receiver systems parameters (e.g., transmitted laser power $\left(P_{0}\right)$, efficiency of the transmitting and receiving optics $\left(\eta_{T X}, \eta_{R X}\right)$, output beam diameter and divergence $\left(D_{L}, \alpha_{T}\right)$, transmitter/receiver LOS geometry, etc.). Therefore, using two identical Lambertian targets placed at slant-ranges $d_{1}$ and $d_{2}$ respectively from the laser transmitter/receiver with a similar LOS geometry, and assuming that the extinction coefficient is constant in the slant-ranges considered, the following expressions can be written for the two anodic voltages measured at the receiver using target $\mathrm{n}^{\circ} 1\left(V_{l}\right)$ and $\operatorname{target}^{\circ} 2\left(V_{2}\right)$ :

$$
V_{1}=R_{L} \cdot R_{S} \cdot\left(K_{S Y S} \cdot \rho \cdot \frac{1}{d_{1}^{2}} \cdot e^{-2 \gamma d_{1}}\right)
$$




$$
V_{2}=R_{L} \cdot R_{S} \cdot\left(K_{S Y S} \cdot \rho \cdot \frac{1}{d_{2}^{2}} \cdot e^{-2 \gamma d_{2}}\right)
$$

It is reasonable to assume that, measuring the anodic voltages $V_{1}$ and $V_{2}$, all system parameters remain constant, except the transmitted laser power $\left(P_{0}\right)$ which may vary significantly in the time intervals where the two measurement sessions are performed. With these assumptions, we can write the following expressions:

$$
\begin{aligned}
& V_{1}=K \cdot P_{01} \cdot \frac{e^{-2 \gamma d_{1}}}{d_{1}{ }^{2}} \\
& V_{2}=K \cdot P_{02} \cdot \frac{e^{-2 \gamma d_{2}}}{d_{2}{ }^{2}}
\end{aligned}
$$

where $P_{01}$ and $P_{02}$ are the transmitted laser powers, and the factor $K$ contains all constant terms. Therefore:

$$
\frac{V_{1}}{V_{2}}=\frac{P_{01}}{P_{02}} \cdot \frac{d_{2}^{2}}{d_{1}^{2}} \cdot e^{2 \gamma\left(d_{2}-d_{1}\right)}
$$

Finally, we obtain:

$$
\gamma=\frac{1}{2 \Delta d} \cdot \ln \left[\frac{\left(\frac{V_{1}}{P_{01}}\right) \cdot d_{1}{ }^{2}}{\left(\frac{V_{2}}{P_{02}}\right) \cdot d_{2}{ }^{2}}\right]
$$

where the difference of the system to target slant-ranges $\left(d_{1}-d_{2}\right)$ has been replaced by the symbol $\Delta d$. It should be noted that all parameters contributing to the constant $K$ do not affect the measurements (i.e., knowledge of these parameters is not required if their value remains constant during the measurements performed on target $n^{\circ} 1$ and $n^{\circ}$ 2). Obviously, the accuracy in the measurement of $\gamma$ is affected by: 1) the error in measuring the distances $d_{1}$ and $d_{2}$; 2 ) the error in measuring the voltages $V_{1}$ and $V_{2}$; and 3) the error in measuring the powers $P_{01}$ and $P_{02}$. Therefore, considering the errors relative to the measured parameters $\left(\sigma_{d 1}, \sigma_{d 2}, \sigma_{V 1}, \sigma_{V 2}, \sigma_{P 01}, \sigma_{P 02}\right)$, we can write:

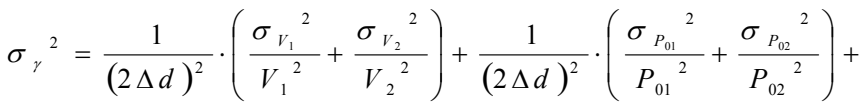

$$
\begin{aligned}
& +\frac{\gamma^{2}}{\Delta d^{2}} \cdot\left(d_{2}+\frac{1}{\gamma}\right)^{2} \cdot \frac{\sigma_{d_{2}}{ }^{2}}{d_{2}{ }^{2}}+\frac{\gamma^{2}}{\Delta d^{2}} \cdot\left(d_{1}+\frac{1}{\gamma}\right)^{2} \cdot \frac{{\sigma_{d_{1}}}^{2}}{d_{1}{ }^{2}}
\end{aligned}
$$

Assuming that the error $\sigma_{d}$ and the relative errors $\sigma_{V} / V$ and $\sigma_{P 0} / P_{0}$ are the same for the measurements performed with target $\mathrm{n}^{\circ} 1$ and target $\mathrm{n}^{\circ} 2$, we have:

$$
\sigma_{\gamma}^{2}=\frac{1}{2 \Delta d^{2}} \cdot\left(\frac{\sigma_{V}{ }^{2}}{V^{2}}+\frac{{\sigma_{P_{0}}}^{2}}{P_{0}^{2}}\right)+\frac{\gamma^{2}}{\Delta d^{2}} \cdot\left[\left(d_{1}+\frac{1}{\gamma}\right)^{2} \cdot \frac{\sigma_{d}{ }^{2}}{d_{1}{ }^{2}}+\left(d_{2}+\frac{1}{\gamma}\right)^{2} \cdot \frac{\sigma_{d}{ }^{2}}{d_{2}{ }^{2}}\right]
$$

Rearranging the terms, we obtain:

$$
\sigma_{\gamma}=\frac{1}{\Delta d} \cdot \sqrt{\left\{\frac{1}{2} \cdot\left(\frac{\sigma_{V}{ }^{2}}{V^{2}}+\frac{\sigma_{P_{0}}{ }^{2}}{P_{0}{ }^{2}}\right)+\gamma^{2} \cdot\left[\left(d_{1}+\frac{1}{\gamma}\right)^{2} \cdot \frac{\sigma_{d}{ }^{2}}{d_{1}{ }^{2}}+\left(d_{2}+\frac{1}{\gamma}\right)^{2} \cdot \frac{\sigma_{d}{ }^{2}}{\left.d_{2}{ }^{2}\right]}\right\}\right.}
$$

Thus, it is evident that the error in the measurement of $\gamma$ is strongly affected by the distance between the two targets. For instance, in the case of laser system with transmitter/receiver parameters, $\sigma_{V} / V=5 \%$ and $\sigma_{P O} / P_{O}=2 \%$. Assuming $\sigma_{d}=1 \mathrm{~m}, d_{1}=800 \mathrm{~m}, \Delta d=100 \mathrm{~m}, d_{2}=900 \mathrm{~m}, \gamma=7 \times 10^{-4} \mathrm{~m}^{-1}$, from Eq. (31) we obtain a relative 
measurement error $\sigma_{\gamma} / \gamma$ of about $54 \%$. Obviously, doubling the distance between the two targets (e.g, assuming $\Delta d$ $=200 \mathrm{~m}$ and $d_{2}=1000 \mathrm{~m}$ ), the estimated relative error would be $27 \%$ (half of the previous case). Assuming that the laser platform and target coordinates can be determined with a $\sigma_{d} \leq 0.01$, we obtain:

$$
\begin{aligned}
& \frac{1}{2} \cdot\left(\frac{\sigma_{V}{ }^{2}}{V^{2}}+\frac{{\sigma_{P_{o}}}^{2}}{P_{O}{ }^{2}}\right) \gg \gamma^{2} \cdot\left[\left(d_{1}+\frac{1}{\gamma}\right)^{2} \cdot \frac{{\sigma_{d}}^{2}}{d_{1}^{2}}+\left(d_{2}+\frac{1}{\gamma}\right)^{2} \cdot \frac{\sigma_{d}{ }^{2}}{d_{2}^{2}}\right] \\
& \sigma_{\gamma} \cong \frac{1}{\Delta d} \cdot \sqrt{\frac{1}{2} \cdot\left(\frac{\sigma_{V}{ }^{2}}{V^{2}}+\frac{{\sigma_{P_{o}}}^{2}}{P_{o}{ }^{2}}\right)}
\end{aligned}
$$

Assuming $\Delta d=1000 \mathrm{~m}$, the estimated measurement error would be:

$$
\sigma_{\gamma} \cong \frac{1}{\Delta d} \cdot \sqrt{\frac{1}{2} \cdot\left(\frac{\sigma_{V}{ }^{2}}{V^{2}}+\frac{{\sigma_{P_{o}}}^{2}}{P_{O}{ }^{2}}\right)}=3.81 \cdot 10^{-5} \mathrm{~m}^{-1}
$$

Since in general $\gamma>10^{-4} \mathrm{~m}^{-1}$, we obtain a maximum relative error $\sigma_{\gamma} / \gamma$ of about $4 \%$.

\section{Experimental Results}

In this section we present experimental results relative to the test activities performed using the proposed LEM1/EMT-2 technique (calibrated NIR camera). It should be noted that, during the initial phases of the test campaign, some trials were performed with LEM-1/EMT-1 and LEM-1/EMT-2 from a range of $2 \mathrm{~km}$ and the results compared with the LEM-2 measurements $\left(d_{1}=500 \mathrm{~m}, \Delta d=1500 \mathrm{~m}, d_{2}=2000 \mathrm{~m}\right.$,). Using samples of 300 measurements, the standard deviation of the observed differences was 3.6\% for LEM-1/EMT-1 and 2.5\% for LEM-1/EMT-2. The dedicated LEM-1/EMT-2 experimental campaign presented here included both ground and flight test activities performed with laser systems operating in the NIR at $\lambda=1064 \mathrm{~nm}$ (Nd:YAG) and $\lambda=1550 \mathrm{~nm}$ (Erbium-fibre). During these test activities measurements were performed of horizontal and oblique/vertical path atmospheric transmission up to altitudes of $22,000 \mathrm{ft} \mathrm{AGL}$, in a large variety of atmospheric conditions.

\subsection{Propagation Trials at $\lambda=1064 \mathrm{~nm}$}

Propagation trials at $\lambda=1064 \mathrm{~nm}$ were performed at the Air Force Laser Test Range in Sardinia (Italy). The laser system was positioned along the target normal at a distance of $2.5 \mathrm{~km}, 4 \mathrm{~km}$ and $5.5 \mathrm{~km}$. The target Mean Sea Level (MSL) altitude was about $500 \mathrm{~m}$ and the maximum altitude difference between the laser transmitter and the target was about $140 \mathrm{~m}$ at a distance of $5.5 \mathrm{~km}$. The geometry of the $\lambda=1064 \mathrm{~nm}$ propagation tests performed at the range are shown in Fig. 8. Table 10 shows the relevant data describing the meteorological conditions in which the atmospheric propagation measurements were performed (dry-air conditions). The various test cases have been grouped for classes of visibility and the corresponding International Visibility Code (IVC) classes are reported. When significant variations of $T$ and/or $R H$ were observed during the measurements, only the average values calculated in the relevant time intervals have been reported. The prevailing wind direction/intensity during the measurements is listed with respect to the laser to target slant-path (usual counter-clockwise convention). The values of the Turbulence Structure Constant $\left(C_{n}\right)$ were determined using the SCINTEC BLS900 laser scintillometer, with a measurement baseline of $5 \mathrm{~km}$ between transmitter and receiver (along the target normal). For each case listed in Table 10, a minimum of 25 energy measurements were performed (samples of 25 to 50 laser spot measurements were used) using at least two of the laser system locations shown in Fig. 8. Dry-air extinction tests were performed in all meteorological conditions listed in Table 11 only with a system to target slant-range (SR) of $2.5 \mathrm{~km}$. With $\mathrm{SR}=4 \mathrm{~km}$ and $\mathrm{SR}=5.5 \mathrm{~km}$, extinction tests were performed in a representative sub-set of dry-air meteorological conditions. Rain extinction tests were not performed at $\lambda=1064 \mathrm{~nm}$. Transmittance and extinction coefficient values relative to the various test cases (i.e., meteorological conditions listed in Table 10), calculated using the ESLM model with $\mathrm{SR}=1 \mathrm{~km}$, are listed in Table 11 . 


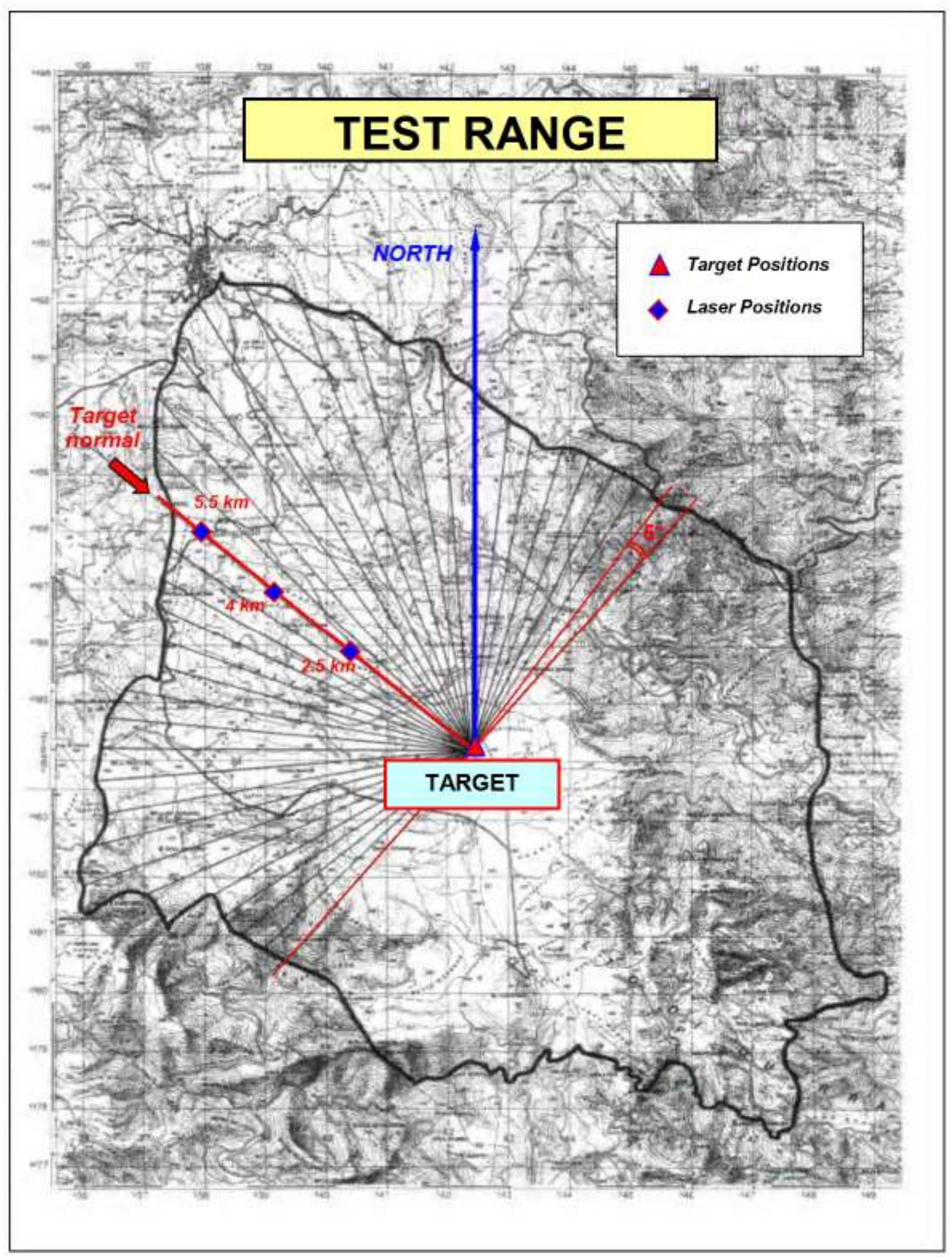

Figure 8. Geometry of atmospheric propagation measurements at $\lambda=1064 \mathrm{~nm}$. 
Table 10. Meteorological data for dry-air propagation measurements at $\lambda=1064 \mathrm{~nm}$.

\begin{tabular}{|c|c|c|c|c|c|c|c|c|}
\hline Group & Case & $\begin{array}{c}V \\
(\mathrm{~km})\end{array}$ & $\begin{array}{l}\text { RH } \\
\text { (\%) }\end{array}$ & $\begin{array}{c}T \\
\left({ }^{\circ} \mathrm{C}\right)\end{array}$ & $C_{n}$ & Cloud & $\begin{array}{l}\text { Wind } \\
\text { (\%/kts) }\end{array}$ & $I V C$ \\
\hline \multirow[t]{3}{*}{$I$} & $A$ & 2.5 & 82 & 24 & $6.77^{*} 10^{-8}$ & $6 / 8$ & $0 / 0$ & \multirow{3}{*}{ Haze } \\
\hline & $B$ & 3.0 & 85 & 15 & $1.80^{*} 10^{-8}$ & $5 / 8$ & $0 / 0$ & \\
\hline & $c$ & 3.5 & 76 & 23 & $9.86^{*} 10^{-7}$ & $7 / 8$ & $92 / 2$ & \\
\hline \multirow[t]{3}{*}{ II } & $A$ & 5 & 73 & 25 & $8.79^{*} 10^{-8}$ & $3 / 8$ & $0 / 0$ & \multirow{6}{*}{ Light Haze } \\
\hline & $B$ & 6.0 & 66 & 27 & $6.67^{*} 10^{-8}$ & $4 / 8$ & $237 / 3$ & \\
\hline & $c$ & 7.0 & 68 & 7 & $1.82^{*} 10^{-7}$ & $7 / 8$ & $0 / 0$ & \\
\hline \multirow[t]{3}{*}{ III } & $A$ & 8.0 & 67 & 24 & $8.96^{*} 10^{-8}$ & $3 / 8$ & $0 / 0$ & \\
\hline & $B$ & 8.5 & 58 & 28 & $6.70^{*} 10^{-8}$ & $3 / 8$ & $120 / 5$ & \\
\hline & $c$ & 9.0 & 64 & 30 & $2.92^{*} 10^{-7}$ & $4 / 8$ & $0 / 0$ & \\
\hline \multirow[t]{4}{*}{ IV } & $A$ & 10.0 & 51 & 20 & $7.16^{*} 10^{-7}$ & $2 / 8$ & $40 / 6$ & \multirow{7}{*}{ Clear } \\
\hline & $B$ & 10.5 & 58 & 28 & $1.87^{*} 10^{-7}$ & $1 / 8$ & $95 / 12$ & \\
\hline & C & 11 & 51 & 18 & $6.39^{*} 10^{-8}$ & $2 / 8$ & $120 / 8$ & \\
\hline & $D$ & 12.5 & 48 & 32 & $8.56^{*} 10^{-7}$ & $3 / 8$ & $0 / 0$ & \\
\hline \multirow[t]{3}{*}{$v$} & $A$ & 14.5 & 52 & 18 & $1.09^{*} 10^{-8}$ & $2 / 8$ & $22 / 4$ & \\
\hline & B & 15.0 & 44 & 32 & $4.87^{*} 10^{-7}$ & $3 / 8$ & $320 / 7$ & \\
\hline & $c$ & 18.5 & 56 & 24 & $7.98^{*} 10^{-8}$ & $0 / 8$ & $35 / 5$ & \\
\hline \multirow[t]{4}{*}{ VI } & $A$ & 20.5 & 40 & 31 & $4.49^{*} 10^{-8}$ & $0 / 8$ & $0 / 0$ & \multirow{4}{*}{ Very Clear } \\
\hline & $B$ & 22.5 & 41 & 35 & $5.87^{*} 10^{-7}$ & $2 / 8$ & $25 / 8$ & \\
\hline & $c$ & 25.0 & 47 & 35 & $7.56^{*} 10^{-7}$ & $1 / 8$ & $125 / 10$ & \\
\hline & $D$ & 34.0 & 35 & 32 & $6.84^{*} 10^{-8}$ & $0 / 8$ & $15 / 7$ & \\
\hline
\end{tabular}

The extinction coefficients in Table 11 were computed from model transmittances, using the simple equation:

$$
\gamma=-\frac{\ln \tau}{S R}
$$

However, it is important to observe that, although the ESLM model provides independent estimates of both absorptive transmittance $\left(\tau_{a i}\right)$ and scattering transmittance $\left(\tau_{s i}\right)$, only the scattering contribution to the extinction coefficient $\left(\gamma_{s i}\right)$ is independent of range. In fact, according to the ESLM model, as $w<54$ for all cases in Table 6, the absorptive transmittance is given by:

$$
\tau_{a i}=e^{-0.0363 \cdot \sqrt{w}}
$$

Therefore, in this case, the absorptive extinction coefficient $\left(\gamma_{a i}\right)$ is given by:

$$
\gamma_{a i}=0.0363 \cdot A H \cdot \frac{1}{\sqrt{S R}}
$$

where the SR dependency of $\gamma_{a i}$ is evident (obviously, for SR $=1 \mathrm{~km}$ the model $\gamma_{a i}$ becomes a function of $A H$ only). 
Table 11. Calculated extinction coefficients for dry-air conditions $(\mathrm{SR}=2.5 \mathrm{~km})$.

\begin{tabular}{|c|c|c|c|c|}
\hline Group & Case & IVC Category & Model $\tau$ & Model $\gamma(\mathrm{km}-1)$ \\
\hline \multirow[t]{3}{*}{$I$} & A & \multirow{3}{*}{ Haze } & 0.077 & 1.025 \\
\hline & B & & 0.127 & 0,824 \\
\hline & C & & 0.168 & 0,714 \\
\hline \multirow[t]{3}{*}{ II } & A & \multirow{6}{*}{$\begin{array}{l}\text { Light } \\
\text { Haze }\end{array}$} & 0.287 & 0,500 \\
\hline & B & & 0.351 & 0,419 \\
\hline & C & & 0.448 & 0,321 \\
\hline \multirow[t]{3}{*}{ III } & A & & 0.455 & 0,315 \\
\hline & B & & 0.470 & 0,302 \\
\hline & C & & 0.476 & 0,297 \\
\hline \multirow[t]{4}{*}{ IV } & A & \multirow{7}{*}{ Clear } & 0.549 & 0,240 \\
\hline & B & & 0.532 & 0,252 \\
\hline & C & & 0.583 & 0,216 \\
\hline & D & & 0.575 & 0,221 \\
\hline \multirow[t]{3}{*}{$v$} & A & & 0.652 & 0,171 \\
\hline & B & & 0.622 & 0,190 \\
\hline & C & & 0.675 & 0,157 \\
\hline \multirow[t]{4}{*}{ VI } & A & \multirow{4}{*}{ Very Clear } & 0.688 & 0,149 \\
\hline & B & & 0.684 & 0,152 \\
\hline & C & & 0.687 & 0,150 \\
\hline & D & & 0.755 & 0,112 \\
\hline
\end{tabular}

For instance, with $S R=10 \mathrm{~km}$, the model $\gamma_{a i}$ is about one third of the value calculated, with the same $R H$ and $T$ conditions, with SR $=1 \mathrm{~km}$. In other words, the ESLM empirical model implies a range dependency of the extinction coefficient, which prevents a direct comparisons of the experimental $\gamma$ values found at a certain SR with $\gamma$ values predicted or measured at a different SR. Although this appears as a limitation of the ESLM model for practical applications, for all SR considered we determined from NIR-camera energy measurements and $\gamma$ using Eq. (69), and compared the calculated values with the experimental results. Therefore, for each SR, different sets of corrections were computed simply by comparing the predicted ESLM $\tau$ and $\gamma$ values with the experimental data. Since the initial phases of the test activity, data collected in various meteorological conditions and with various laser slant-paths, demonstrated moderate discrepancies between the extinction measurements performed with EMT-1 and EMT-2 (i.e., 8\% maximum difference). Furthermore, using the two techniques, no significant correlation was observed between the differences in the measurements and the lengths of the laser slant-paths used to gather the 
experimental data. Table 12 shows the results of transmittance measurements performed using the EMT-2 technique for a laser slant-path of $2.5 \mathrm{~km}$, compared with ESLM model computations.

Table 12. Transmittance data and ESLM model corrections $(\lambda=1064 \mathrm{~nm}-\mathrm{SR}=2.5 \mathrm{~km})$.

\begin{tabular}{|c|c|c|c|c|c|c|c|}
\hline Group & Case & $\begin{array}{c}\text { IVC } \\
\text { Category }\end{array}$ & $\underset{\left(\mathrm{km}^{-1}\right)}{\operatorname{Experim}} \gamma$ & $\begin{array}{c}\text { Model } \gamma \\
\left(\mathrm{km}^{-1}\right)^{\gamma}\end{array}$ & $\begin{array}{c}\text { Error } \\
(\%)\end{array}$ & $\begin{array}{l}\text { Group } \\
\text { Corr. }\end{array}$ & $\begin{array}{c}\text { IVC Cat. } \\
\text { Corr. }\end{array}$ \\
\hline \multirow[t]{3}{*}{$I$} & A & \multirow{3}{*}{ Haze } & 0.967 & 1,025 & -5.64 & \multirow[t]{3}{*}{0.923} & \multirow[t]{3}{*}{0.923} \\
\hline & B & & 0.757 & 0,824 & -8.09 & & \\
\hline & C & & 0.647 & 0,714 & -9.34 & & \\
\hline \multirow[t]{3}{*}{ II } & A & \multirow{6}{*}{$\begin{array}{l}\text { Light } \\
\text { Haze }\end{array}$} & 0.437 & 0,500 & -12.62 & \multirow[t]{3}{*}{0.857} & \multirow[t]{6}{*}{0.846} \\
\hline & B & & 0.360 & 0,419 & -14.15 & & \\
\hline & C & & 0.269 & 0,321 & -16.10 & & \\
\hline \multirow[t]{3}{*}{ III } & A & & 0.265 & 0,315 & -15.99 & \multirow[t]{3}{*}{0.836} & \\
\hline & B & & 0.249 & 0,302 & -17.59 & & \\
\hline & C & & 0.250 & 0,297 & -15.75 & & \\
\hline \multirow[t]{4}{*}{ IV } & A & \multirow{7}{*}{ Clear } & 0.186 & 0,240 & -22.70 & \multirow[t]{4}{*}{0.772} & \multirow[t]{7}{*}{0.750} \\
\hline & B & & 0.207 & 0,252 & -18.20 & & \\
\hline & C & & 0.163 & 0,216 & -24.66 & & \\
\hline & D & & 0.165 & 0,221 & -25.47 & & \\
\hline \multirow[t]{3}{*}{$v$} & A & & 0.122 & 0,171 & -28.57 & \multirow[t]{3}{*}{0.728} & \\
\hline & B & & 0.140 & 0,190 & -26.11 & & \\
\hline & C & & 0.115 & 0,157 & -27.01 & & \\
\hline \multirow[t]{4}{*}{ VI } & A & \multirow{4}{*}{$\begin{array}{l}\text { Very } \\
\text { Clear }\end{array}$} & 0.107 & 0,149 & -28.24 & \multirow[t]{4}{*}{0.692} & \multirow[t]{4}{*}{0.692} \\
\hline & B & & 0.106 & 0,152 & -30.21 & & \\
\hline & C & & 0.110 & 0,150 & -26.64 & & \\
\hline & D & & 0.070 & 0,112 & -37.99 & & \\
\hline
\end{tabular}

In all cases, the measured transmittance values (i.e., average of 25-50 spot measurements) were greater than the values computed using the ESLM model. The observed differences between measured and ESLM transmittances varied between $10.52 \%$ and $16.64 \%$. The ESLM transmittance model corrections computed for each group and for each IVC category are also listed in Table 12. It is evident, looking at the results in Table 12 and at their graphical representation in Fig. 9, that the difference between predicted and measured transmittance decreases significantly as atmospheric visibility increases. 


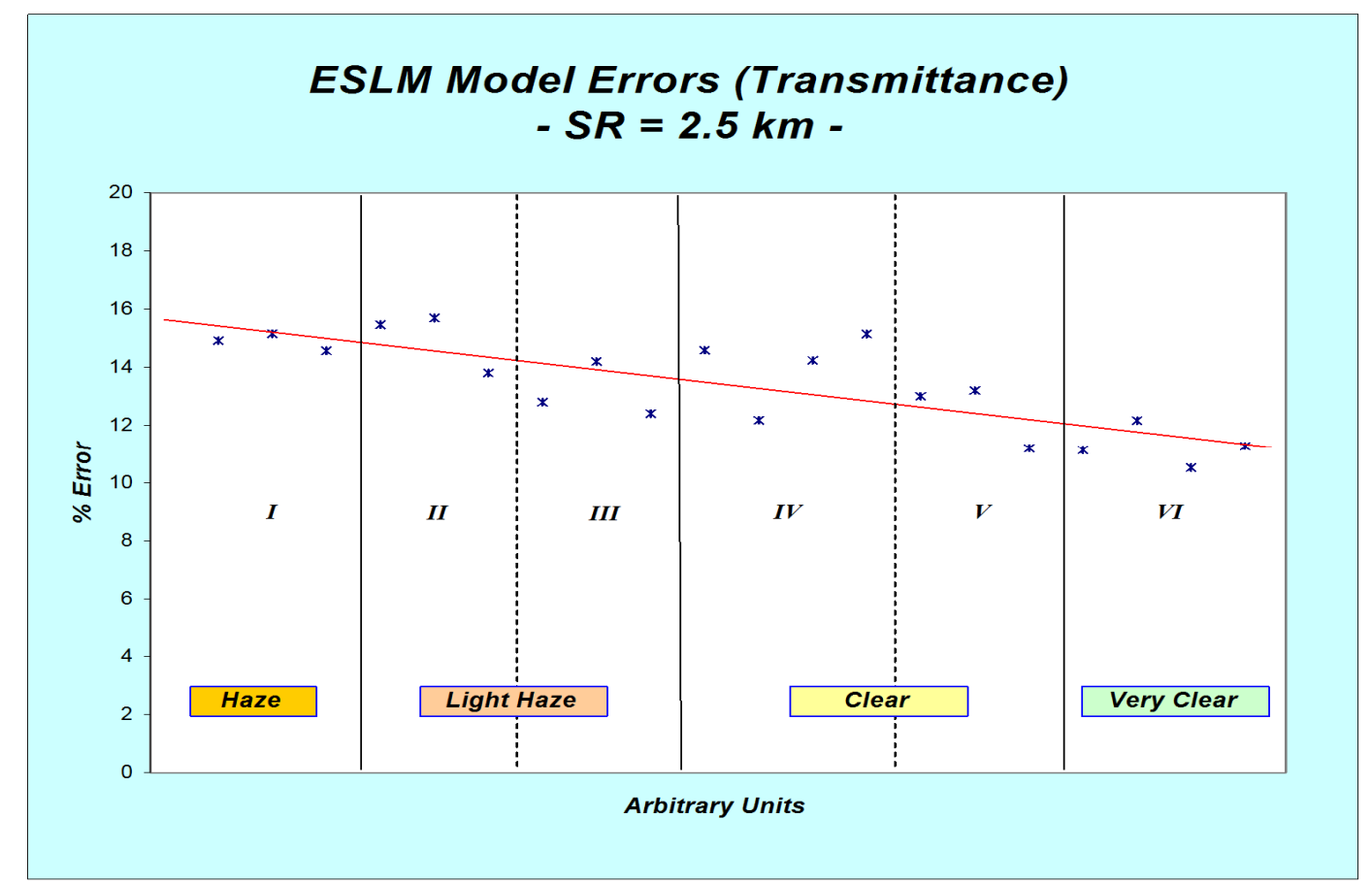

Figure 9. ESLM model errors (transmittance) for $\mathrm{SR}=2.5 \mathrm{~km}$.

Experimental data and error computations relative to the measurements performed with $\mathrm{SR}=4 \mathrm{~km}$ and $\mathrm{SR}=5.5 \mathrm{~km}$ are presented in Tables 13 and 14. Although with these SR's measurements were not performed in all meteorological conditions listed in Table 10, looking at the available data it appears evident that the ESLM model errors are comparable with the errors computed for $\mathrm{SR}=2.5 \mathrm{~km}$.

Table 13. Transmittance data and ESLM model corrections $(\lambda=1064 \mathrm{~nm}-\mathrm{SR}=4 \mathrm{~km})$.

\begin{tabular}{|c|c|c|c|c|c|c|c|}
\hline Group & Case & $\begin{array}{c}\text { IVC } \\
\text { Categ. }\end{array}$ & Experim. $\gamma$ & Model $\gamma$ & $\begin{array}{l}\text { Error } \\
(\%)\end{array}$ & $\begin{array}{l}\text { Group } \\
\text { Corr. }\end{array}$ & $\begin{array}{c}\text { IVC Cat. } \\
\text { Corr. }\end{array}$ \\
\hline \multirow[t]{2}{*}{ II } & A & \multirow{4}{*}{$\begin{array}{l}\text { Light } \\
\text { Haze }\end{array}$} & 0.430 & 0.480 & -10.40 & \multirow[t]{2}{*}{0.872} & \multirow[t]{4}{*}{0.849} \\
\hline & C & & 0.262 & 0.309 & -15.30 & & \\
\hline \multirow[t]{2}{*}{ III } & B & & 0.239 & 0.283 & -15.48 & \multirow[t]{2}{*}{0.827} & \\
\hline & C & & 0.223 & 0.276 & -19.17 & & \\
\hline \multirow[t]{2}{*}{ IV } & A & \multirow{3}{*}{ Clear } & 0.179 & 0.225 & -20.59 & \multirow[t]{2}{*}{0.810} & \multirow[t]{3}{*}{0.787} \\
\hline & B & & 0.192 & 0.233 & -17.45 & & \\
\hline$v$ & C & & 0.107 & 0.140 & -23.50 & 0.765 & \\
\hline VI & A & $\begin{array}{l}\text { Very } \\
\text { Clear }\end{array}$ & 0.096 & 0.132 & -27.19 & 0.728 & 0.728 \\
\hline
\end{tabular}

Table 14. Transmittance data and ESLM model corrections $(\lambda=1064 \mathrm{~nm}-\mathrm{SR}=5.5 \mathrm{~km})$ 


\begin{tabular}{|c|c|c|c|c|c|c|c|}
\hline Group & Case & $\begin{array}{c}\text { IVC } \\
\text { Categ. }\end{array}$ & Experim. $\gamma$ & Model $\gamma$ & $\begin{array}{c}\text { Error } \\
(\%)\end{array}$ & $\begin{array}{l}\text { Group } \\
\text { Corr. }\end{array}$ & $\begin{array}{c}\text { IVC Cat. } \\
\text { Corr. }\end{array}$ \\
\hline \multirow[t]{2}{*}{ II } & B & \multirow{4}{*}{$\begin{array}{l}\text { Light } \\
\text { Haze }\end{array}$} & 0.346 & 0.388 & -10.80 & \multirow[t]{2}{*}{0.881} & \multirow[t]{4}{*}{0.850} \\
\hline & C & & 0.264 & 0.304 & -13.00 & & \\
\hline \multirow[t]{2}{*}{ III } & B & & 0.228 & 0.272 & -16.16 & \multirow[t]{2}{*}{0.818} & \\
\hline & C & & 0.211 & 0.264 & -20.20 & & \\
\hline \multirow[t]{2}{*}{ IV } & A & \multirow{4}{*}{ Clear } & 0.176 & 0.217 & -19.09 & \multirow[t]{2}{*}{0.809} & \multirow[t]{4}{*}{0.774} \\
\hline & B & & 0.178 & 0.223 & -19.29 & & \\
\hline \multirow[t]{2}{*}{$v$} & A & & 0.113 & 0.150 & -24.71 & \multirow[t]{2}{*}{0.738} & \\
\hline & B & & 0.116 & 0.161 & -27.66 & & \\
\hline \multirow[t]{2}{*}{ VI } & B & \multirow{2}{*}{$\begin{array}{l}\text { Very } \\
\text { Clear }\end{array}$} & 0.090 & 0.122 & -26.53 & \multirow[t]{2}{*}{0.703} & \multirow[t]{2}{*}{0.703} \\
\hline & D & & 0.058 & 0.087 & -32.95 & & \\
\hline
\end{tabular}

The ESLM model errors for computing $\gamma$, relative to the various test cases with $\mathrm{SR}=2.5 \mathrm{~km}$ are shown in Fig. 10 . The error trends were not significantly affected by the system to target SR and, in all cases, the ESLM model always over-estimated the extinction coefficient (i.e., under-estimated transmittance). Therefore, the experimental results are not in contrast with the $1 / \sqrt{S R}$ dependency of $\gamma_{a i}$ implied in the ESLM empirical model. The under estimation of $\tau$ can be explained observing that the ESLM model is a two components model (i.e., scattering transmittance $\tau_{s i}$ and absorptive transmittance $\tau_{a i}$ ) whose empiric equations were derived from independent scattering and absorption measurements, in which either absorption or scattering were neglected due to the particular test conditions [3-6]. On the other hand, the effects of turbulence and other linear and non-linear propagation phenomena not included in the ESLM model, did not seem to significantly affect the energy measurements performed using EMT-2 and the ELOPPLD laser system in the specified test conditions. 


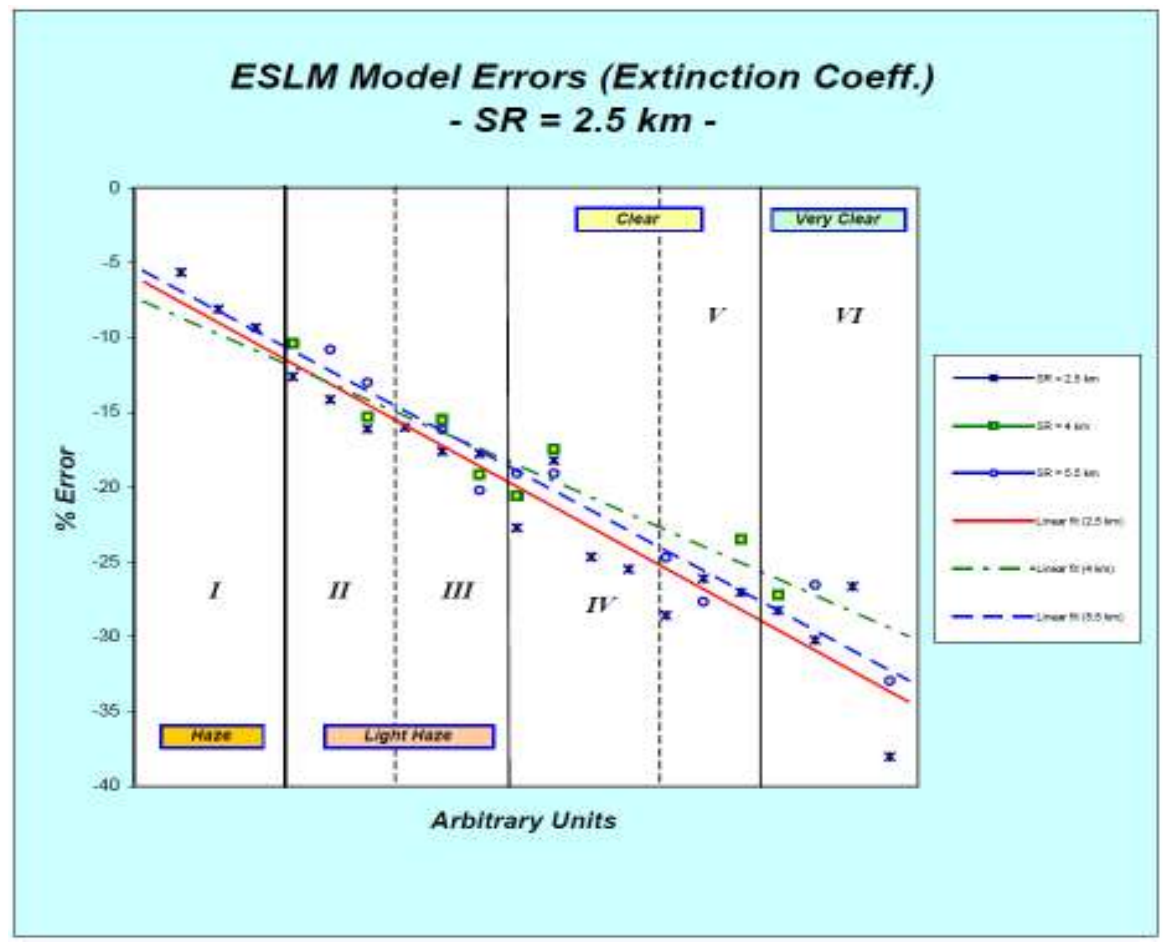

Figure 10. ESLM model errors for computation of $\gamma(\lambda=1064 \mathrm{~nm}-\mathrm{SR}=2.5 \mathrm{~km})$.

\subsection{Propagation Tests at $\lambda=1550 \mathrm{~nm}$}

The parameters describing the meteorological conditions during the propagation trials at $\lambda=1550 \mathrm{~nm}$ are listed in the Tables 15 and 16.

Table 15. Meteorological data for dry-air propagation measurements at $\lambda=1550 \mathrm{~nm}$.

\begin{tabular}{|c|c|c|c|c|c|c|c|c|}
\hline Group & Case & $\begin{array}{c}V \\
(\mathrm{~km})\end{array}$ & $\begin{array}{l}R H \\
(\%)\end{array}$ & $\begin{array}{c}T \\
\left({ }^{\circ} \mathrm{C}\right)\end{array}$ & $C_{n}$ & Cloud & $\begin{array}{l}\text { Wind } \\
\text { (\%/kts) }\end{array}$ & IVC \\
\hline \multirow[t]{2}{*}{1} & $a$ & 3.0 & 82 & 25 & $7.45^{\star} 10^{-8}$ & $5 / 8$ & $92 / 8$ & \multirow{2}{*}{ Haze } \\
\hline & $b$ & 4.0 & 85 & 21 & $4.49^{*} 10^{-8}$ & $3 / 8$ & $95 / 2$ & \\
\hline \multirow[t]{3}{*}{2} & $a$ & 7.0 & 78 & 22 & $5.27^{*} 10^{-8}$ & $5 / 8$ & $0 / 0$ & \multirow{3}{*}{ Light Haze } \\
\hline & $b$ & 8.0 & 67 & 25 & $7.30^{*} 10^{-7}$ & $2 / 8$ & $120 / 5$ & \\
\hline & $c$ & 9.0 & 72 & 29 & $2.65^{*} 10^{-8}$ & $4 / 8$ & $45 / 8$ & \\
\hline \multirow[t]{4}{*}{3} & a & 12.0 & 61 & 23 & $3.15^{\star} 10^{-8}$ & $3 / 8$ & $0 / 0$ & \multirow{4}{*}{ Clear } \\
\hline & $b$ & 15.5 & 49 & 31 & $5.90^{*} 10^{-8}$ & $0 / 8$ & $0 / 0$ & \\
\hline & $c$ & 18.0 & 55 & 28 & $7.66^{*} 10^{-7}$ & $0 / 8$ & $70 / 2$ & \\
\hline & $d$ & 20.0 & 57 & 30 & $5.23^{*} 10^{-7}$ & $2 / 8$ & $54 / 11$ & \\
\hline \multirow[t]{3}{*}{4} & $a$ & 22.5 & 52 & 31 & $5.80 * 10^{-7}$ & $0 / 8$ & $0 / 0$ & \multirow{3}{*}{ Very Clear } \\
\hline & $b$ & 24.0 & 44 & 35 & $4.65^{*} 10^{-7}$ & $0 / 8$ & $130 / 6$ & \\
\hline & $c$ & 28.0 & 57 & 35 & $6.40^{*} 10^{-8}$ & $2 / 8$ & $46 / 7$ & \\
\hline
\end{tabular}


Table 16. Meteorological data for propagation measurements with rain at $\lambda=1550 \mathrm{~nm}$.

\begin{tabular}{|c|c|c|c|c|c|c|c|c|}
\hline Group & Case & $\begin{array}{c}V \\
(\mathrm{~km})\end{array}$ & $\begin{array}{l}R H \\
(\%)\end{array}$ & $\begin{array}{c}T \\
\left({ }^{\circ} \mathrm{C}\right)\end{array}$ & Cn & $\begin{array}{l}\text { Wind } \\
\text { (\%/kts) }\end{array}$ & $\begin{array}{l}\text { Rainfall } \\
\text { (cm/hr) }\end{array}$ & Type of Rain \\
\hline \multirow[t]{3}{*}{5} & a & 3.0 & 100 & 10 & $3.22^{*} 10^{-7}$ & $23 / 4$ & 2.10 & Heavy rain \\
\hline & $\boldsymbol{b}$ & 5.0 & 90 & 12 & $5.90^{*} 10^{-7}$ & $122 / 10$ & 1.45 & Med. Rain \\
\hline & $c$ & 6.0 & 90 & 18 & $8.12^{*} 10^{-8}$ & $15 / 5$ & 0.30 & Light rain \\
\hline
\end{tabular}

The extinction coefficients calculated, for each case listed in the Tables 16 and 17, using the ESLM model, are listed in the Tables 17 and 18 .

Table 17. Calculated extinction coefficients for dry-air.

\begin{tabular}{|c|c|c|c|}
\hline Group & Case & IVC & Model $\gamma(k m-1)$ \\
\hline \multirow[t]{2}{*}{1} & $a$ & \multirow{2}{*}{ Haze } & 1.082 \\
\hline & $b$ & & 0.890 \\
\hline \multirow[t]{3}{*}{2} & $a$ & \multirow{3}{*}{ Light Haze } & 0.689 \\
\hline & $b$ & & 0.661 \\
\hline & $c$ & & 0.671 \\
\hline \multirow[t]{4}{*}{3} & $a$ & \multirow{4}{*}{ Clear } & 0.573 \\
\hline & $b$ & & 0.572 \\
\hline & $c$ & & 0.556 \\
\hline & $d$ & & 0.565 \\
\hline \multirow[t]{3}{*}{4} & $a$ & \multirow{3}{*}{ Very Clear } & 0.555 \\
\hline & $b$ & & 0.556 \\
\hline & $c$ & & 0.579 \\
\hline
\end{tabular}

Table 18. Calculated extinction coefficients for rain.

\begin{tabular}{|c|c|c|c|}
\hline Group & Case & Type of Rain & Model $\gamma(\mathbf{k m}-\mathbf{1})$ \\
\hline \multirow{5}{*}{5} & $\boldsymbol{a}$ & Heavy rain & 2.944 \\
\cline { 2 - 4 } & $\boldsymbol{b}$ & Med. rain & 2,429 \\
\cline { 2 - 4 } & $\boldsymbol{c}$ & Light rain & 1,231 \\
\hline
\end{tabular}


The ESLM extinction coefficients in the Tables 17 and 18 were computed from model transmittances using the equation $\gamma=-\ln \tau / S R$ with $S R=1 \mathrm{~km}$. Experimental data and ESLM model errors relative to the measurements performed in both dry and rainy conditions are presented in the Tables 19 and 20.

Table 19. Dry-air experimental data and ESLM model corrections $(\lambda=1550 \mathrm{~nm})$

\begin{tabular}{|c|c|c|c|c|c|c|c|}
\hline Group & Case & IVC & Model $\gamma$ & Exper. $\gamma$ & Error \% & Case Corr. & $\begin{array}{c}\text { IVC Cat. } \\
\text { Corr. }\end{array}$ \\
\hline \multirow{2}{*}{1} & a & Haze & 1.082 & 0.816 & -24.56 & 0.754 & 0.745 \\
& b & 0.890 & 0.655 & -26.43 & 0.736 & \\
\hline \multirow{2}{*}{2} & a & & 0.689 & 0.446 & $-35,20$ & 0.648 & 0.647 \\
& b & Light Haze & 0.661 & 0.479 & $-27,58$ & 0.724 & \\
& c & & 0.671 & 0.381 & $-43,27$ & 0.567 & \\
\hline \multirow{2}{*}{3} & a & & 0.573 & 0.332 & $-42,10$ & 0.579 & 0.584 \\
& b & Clear & 0.572 & 0.382 & $-33,30$ & 0.667 & \\
& c & & 0.556 & 0.350 & $-37,10$ & 0.629 & \\
& d & & 0.565 & 0.261 & $-53,80$ & 0.462 & \\
\hline \multirow{2}{*}{4} & a & & 0.555 & 0.324 & $-41,60$ & 0.584 & 0.601 \\
& b & Very Clear & 0.556 & 0.354 & $-36,30$ & 0.637 & \\
& c & & 0.579 & 0.337 & $-41,67$ & 0.583 & \\
\hline
\end{tabular}

Table 20. Rain experimental data and ESLM model corrections $(\lambda=1550 \mathrm{~nm})$.

\begin{tabular}{|c|c|c|c|c|c|c|}
\hline Group & Case & Type of Rain & Model $\boldsymbol{\gamma}$ & Exper. $\boldsymbol{\gamma}$ & Error \% & Case Corr. \\
\hline \multirow{2}{*}{5} & $\boldsymbol{a}$ & Heavy rain & 2.596 & 2.266 & -12.70 & 0.873 \\
\cline { 2 - 7 } & $\boldsymbol{b}$ & Med. rain & 2.080 & 2.006 & -3.56 & 0.964 \\
\cline { 2 - 7 } & C & Light rain & 0.864 & 0.729 & -15.67 & 0.843 \\
\hline
\end{tabular}

It is evident that, also at $\lambda=1550 \mathrm{~nm}$, there is a considerable difference between the experimental data and the ESLM dry-air model results. Again, the over estimation of $\gamma$ can be explained observing that the ESLM model is a two components model whose empiric equations were derived from independent scattering and absorption measurements, in which either absorption or scattering were neglected due to the particular test conditions [3-6]. On the other hand, the ESLM model for rainy conditions fitted reasonably well the experimental data, with transmittance differences not exceeding $15.67 \%$ (light rain case).

\subsection{Flight Trials}

Flight test activities were performed using the infrared version of the THOMSON Convertible Laser Designation Pod (CLDP-IR) with $\lambda=1064 \mathrm{~nm}$ and $f=10 \mathrm{~Hz}$, installed on a TORNADO-IDS aircraft. The aim of these tests was to obtain experimental data regarding the variations of the attenuation coefficient at $\lambda=1064 \mathrm{~nm}$ as a function of altitude. In order to cope with this task, it was first of all required to correctly plan the flight sorties and selecting the test points according to the aircraft envelope limitations (including the constrains imposed by laser eye-safety), to the range instrumentation mode of operation and to the CLDP-IR functional characteristics. Two flight sorties 
were executed in days with visibility in excess of $15 \mathrm{~km}$, including four dive manoeuvres at $45^{\circ}, 35^{\circ}, 25^{\circ}$ and $15^{\circ}$ respectively. The dive profiles envelopes are described in the Table 21.

Table 21. Flight profiles envelopes for propagation flight trials.

\begin{tabular}{|c|c|c|c|c|c|c|c|c|}
\hline \multirow{2}{*}{$\begin{array}{c}\text { Profile } \\
\text { Envelope }\end{array}$} & \multicolumn{2}{|c|}{$\mathbf{2 0}$ Dive } & \multicolumn{2}{c|}{$30^{\circ}$ Dive } & \multicolumn{2}{c|}{$\mathbf{4 0}^{\circ}$ Dive } & \multicolumn{2}{c|}{$\mathbf{5 0}^{\circ}$ Dive } \\
\cline { 2 - 9 } & Alt. & Dist. & Alt. & Dist. & Alt. & Dist. & Alt. & Dist. \\
\hline Top & $14000 \mathrm{ft}$ & $12.5 \mathrm{~km}$ & $19000 \mathrm{ft}$ & $11.5 \mathrm{~km}$ & $20000 \mathrm{ft}$ & $9.5 \mathrm{~km}$ & $22000 \mathrm{ft}$ & $8.5 \mathrm{~km}$ \\
\hline Bottom & $6000 \mathrm{ft}$ & $5.5 \mathrm{~km}$ & $7000 \mathrm{ft}$ & $4 \mathrm{~km}$ & $8000 \mathrm{ft}$ & $4 \mathrm{~km}$ & $8000 \mathrm{ft}$ & $3.5 \mathrm{~km}$ \\
\hline
\end{tabular}

When data could not be collected during the dives, straight and level passages were performed parallel to the target surface. In all cases, the CLDP-IR laser was manually activated by the WSO at the required altitudes and grazing angles. The CLDP-IR laser eye-safety envelope is shown in Fig. 12, with superimposed the dive profiles.

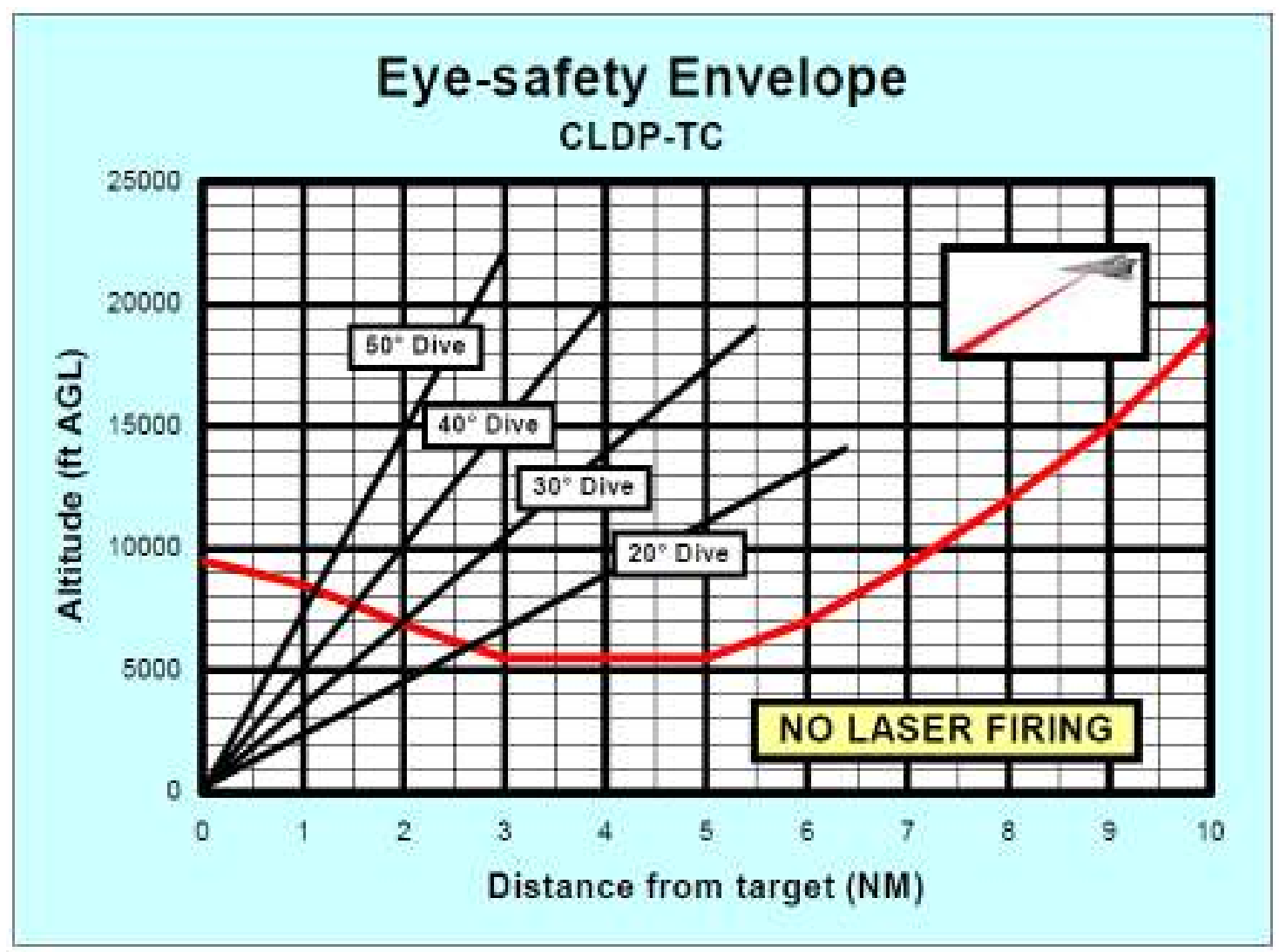

Fig. 12. CLDP-IR eye-safety envelope.

The flights were performed on two successive summer days. The meteorological data collected at the target location during the two sorties are reported in Table 22. 
Table 22. Meteorological data relative to propagation flight trials.

\begin{tabular}{|c|c|c|c|c|c|}
\hline Sortie & $\begin{array}{c}\text { Visibility } \\
(\mathbf{k m})\end{array}$ & $\begin{array}{c}\text { Rel. Humidity } \\
(\%)\end{array}$ & $\begin{array}{c}\text { Temperature } \\
\left({ }^{\circ} \mathbf{C}\right)\end{array}$ & $\begin{array}{c}\text { Wind } \\
(\% / k t s)\end{array}$ & Cloud \\
\hline $\mathbf{1}$ & $16 \mathrm{~km}$ & $57 \%$ & $35^{\circ} \mathrm{C}$ & $120 / 7$ & $0 / 8$ \\
\hline $\mathbf{2}$ & $18 \mathrm{~km}$ & $54 \%$ & $32^{\circ} \mathrm{C}$ & $0 / 0$ & $2 / 8$ \\
\hline
\end{tabular}

Following the planned flight profiles, experimental data collected during the two TORNADO-IDS sorties allowed to estimate the variations of the attenuation coefficient with altitude. Particularly, measuring transmittances for various aircraft grazing angles and altitudes (aircraft instrumented with Differential GPS and equipped with standard barometric/radar altimeters), the following results were found. The experimental data obtained with a grazing angle of $50^{\circ}$ are plotted in Fig. 13. The following linear approximation was found for the ratio of attenuation coefficient to its sea-level value:

$$
\gamma_{\text {atm }}^{H} / \gamma_{\text {atm }}=-1.9568 \cdot 10^{-5} H+0.9663
$$

where $\gamma_{a t m}^{H}$ is the attenuation coefficient of the slant-path, $\gamma_{a t m}$ is the attenuation coefficient at sea-level, and $H$ is the aircraft Mean Sea Level (MSL) altitude in thousands of ft. The second order polynomial fit of the same experimental data is:

$$
\gamma_{\text {atm }}^{H} / \gamma_{\text {atm }}=5.5583 \cdot 10^{-10} H^{2}-3.6243 \cdot 10^{-5} H+1.0810
$$

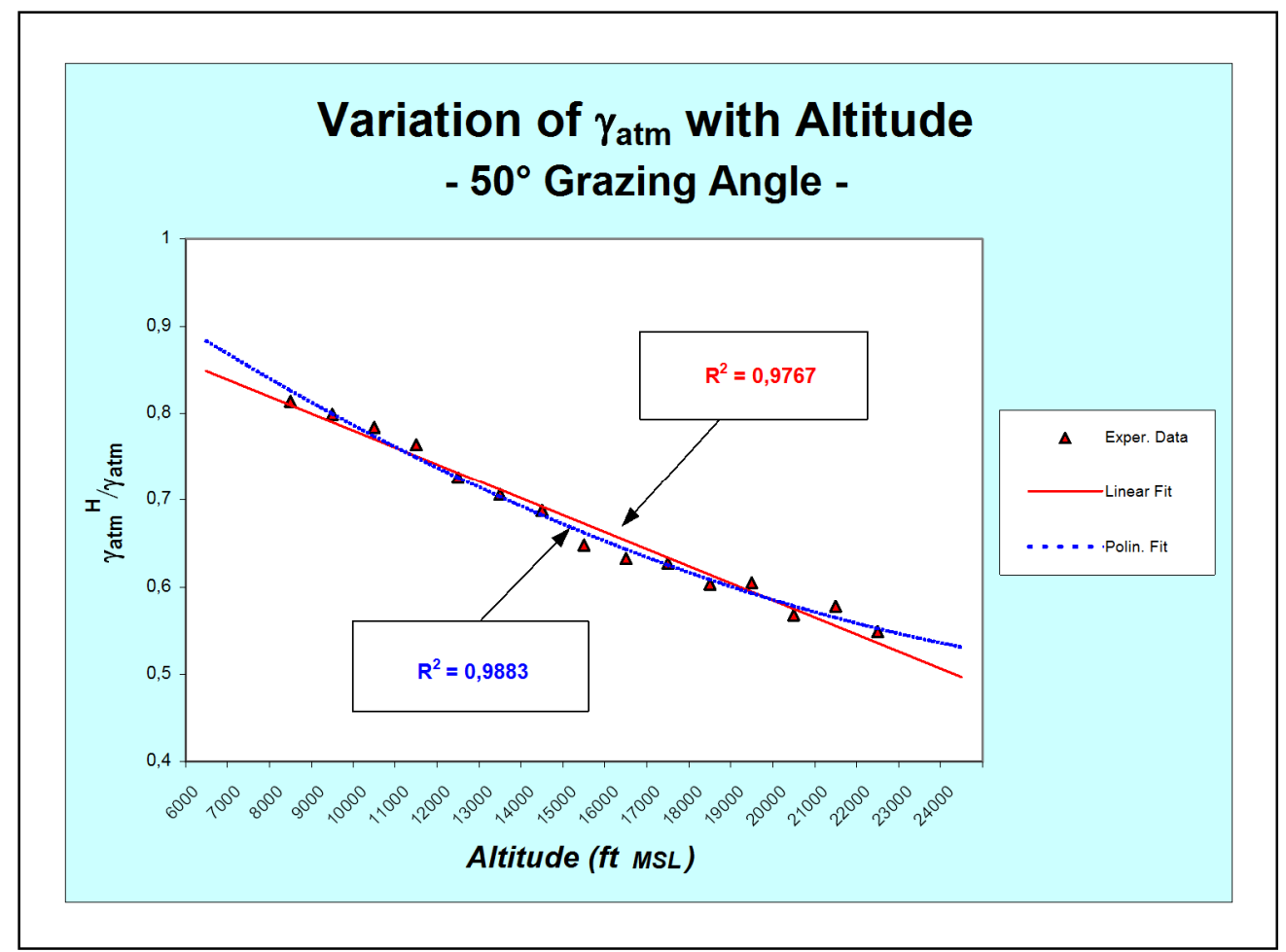

Figure 13. Ratio of the attenuation coefficient to its sea-level value for $50^{\circ}$ grazing slant-paths. 
The experimental data obtained with a $40^{\circ}$ grazing angle are plotted in Fig. 14. The following linear approximation was found for the ratio of attenuation coefficient to its sea-level value:

$$
\gamma_{a t m}^{H} / \gamma_{a t m}=-1.7566 \cdot 10^{5} H+0.9608
$$

The second order polynomial fit of the experimental data is:

$$
\gamma_{a t m}^{H} / \gamma_{a t m}=7.6424 \cdot 10^{-11} H^{2}-1.9706 \cdot 10^{-5}+0.9747
$$

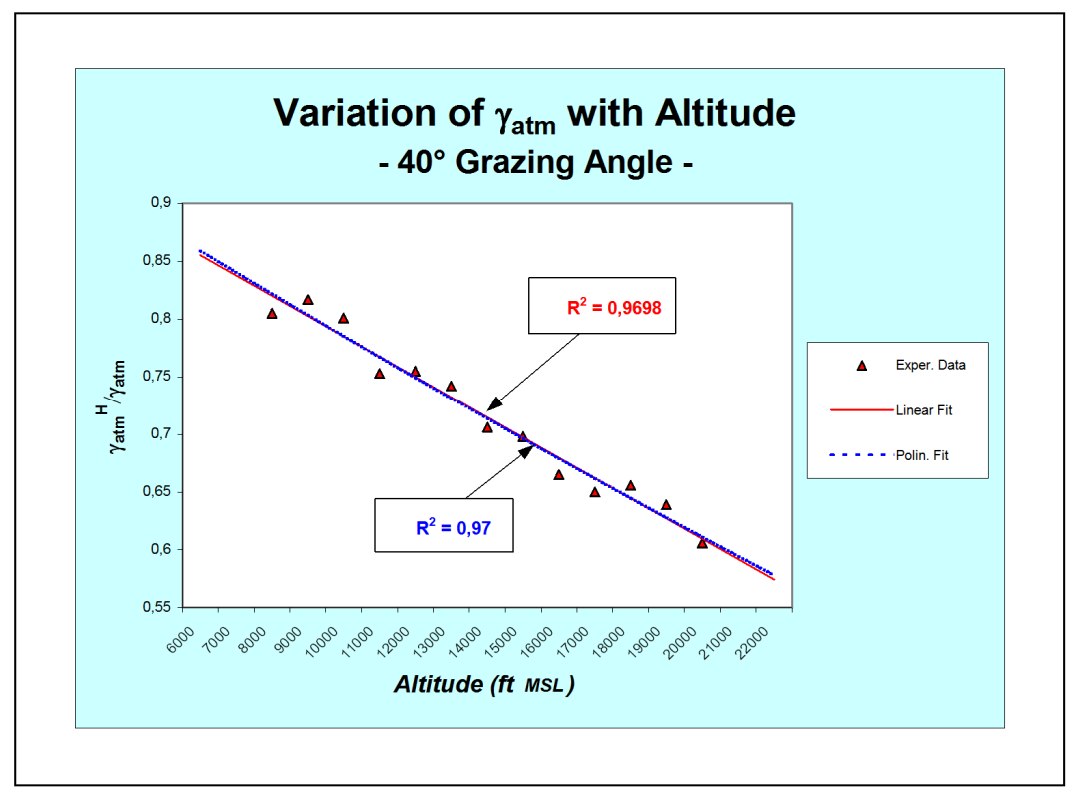

Figure 14. Ratio of the attenuation coefficient to its sea-level value for $40^{\circ}$ grazing slant paths.

The experimental data obtained with a grazing angle of $30^{\circ}$ are plotted in Fig. 15 . The following linear approximation was found for the ratio of attenuation coefficient to its sea-level value:

$$
\gamma_{\text {atm }}^{H} / \gamma_{\text {atm }}=-1.5245 \cdot 10^{-5} H+0.9626
$$

The second order polynomial fit of the same experimental data is:

$$
\gamma_{a t m}^{H} / \gamma_{a t m}=5.3447 \cdot 10^{-10} H^{2}-2.9675 \cdot 10^{-5} H+1.0537
$$




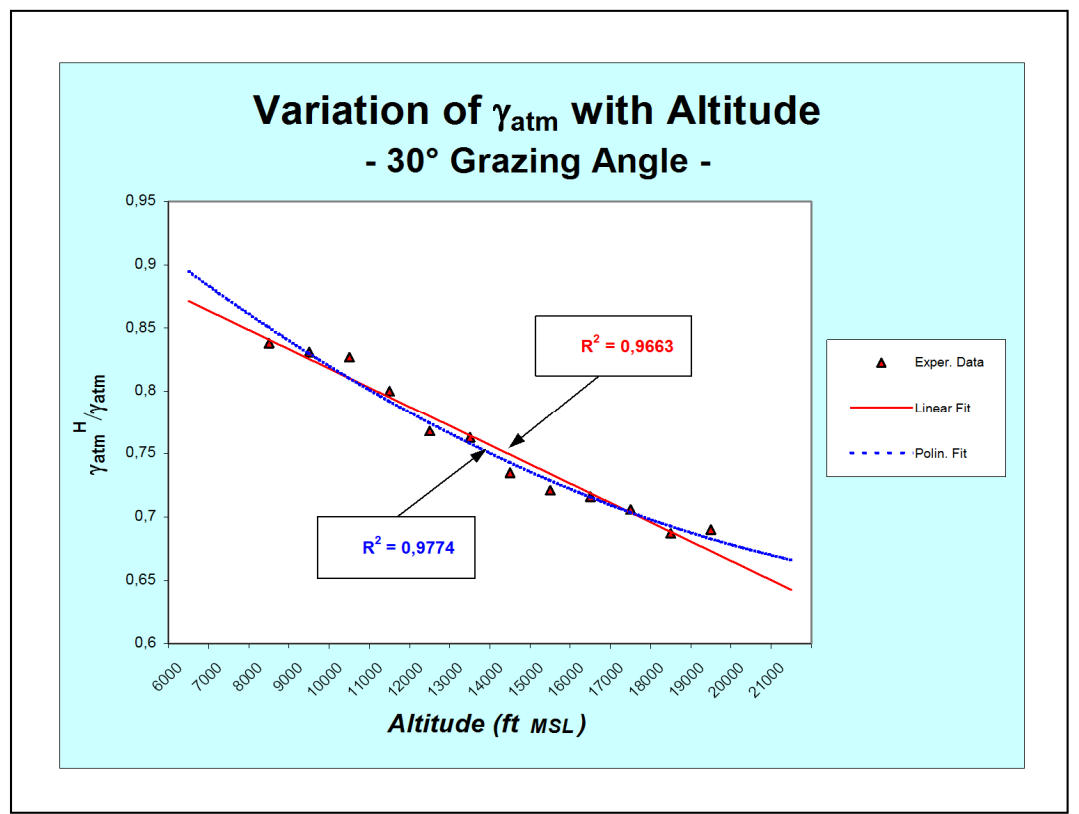

Figure 15. Ratio of the attenuation coefficient to its sea-level value for $30^{\circ}$ grazing slant paths.

The experimental data obtained with manual laser activation during the $20^{\circ}$ dive maneuver are plotted in Fig. 16 . The following linear approximation was found for the ratio of attenuation coefficient to its sea-level value:

$$
\gamma_{\text {atm }}^{H} / \gamma_{\text {atm }}=-1.3758 \cdot 10^{-5} H+0.9530
$$

The second order polynomial fit of the same experimental data is:

$$
\gamma_{a t m}^{H} / \gamma_{a t m}=3.2468 \cdot 10^{-13} H^{2}-1.3765 \cdot 10^{-5} H+0.9531
$$




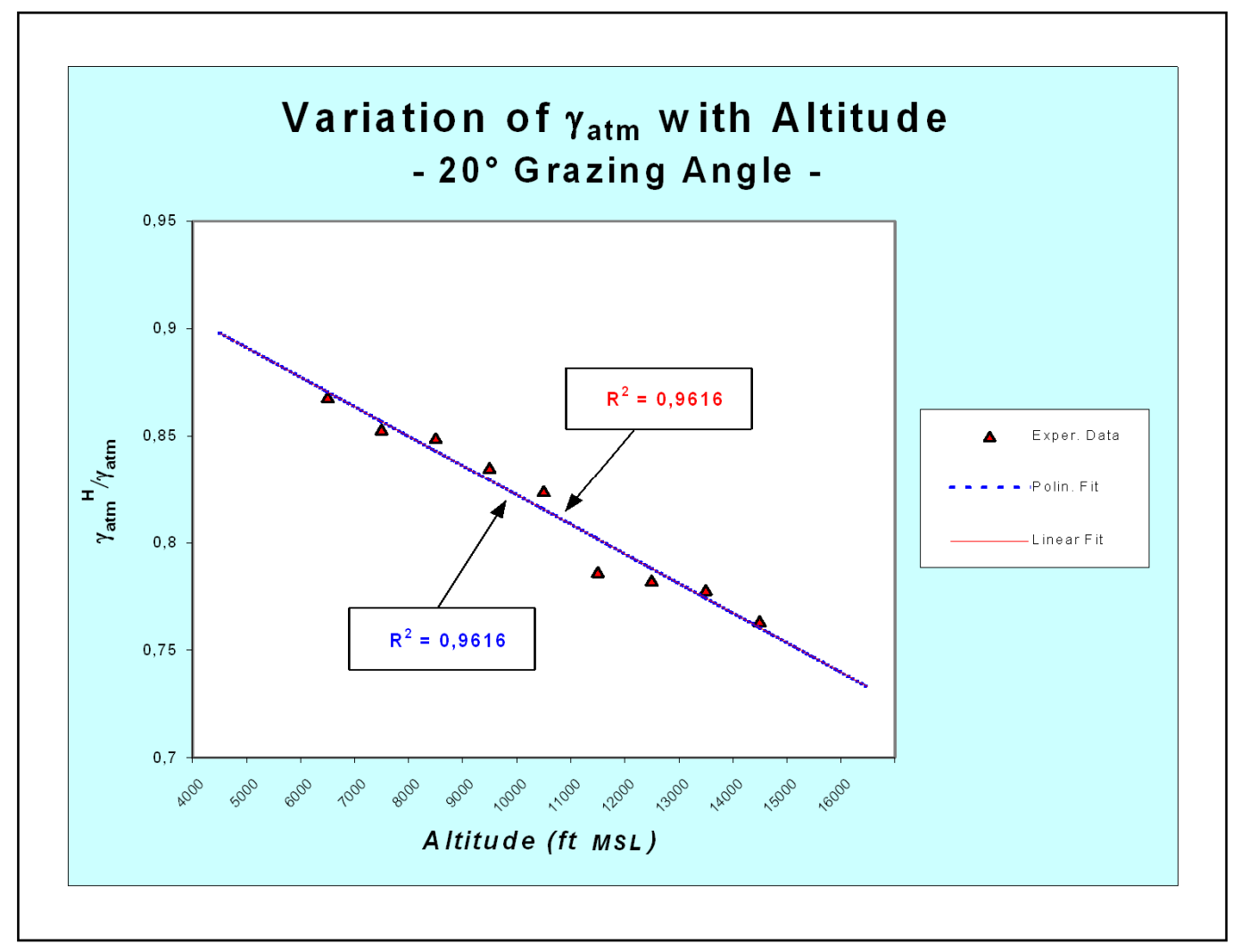

Figure 16. Ratio of the attenuation coefficient to its sea-level value for $20^{\circ}$ grazing slant-paths.

All experimental data collected during the trials are shown in Fig. 17. Looking at the data trends, it is evident that, as the grazing angle $(\xi)$ becomes shallower, $\gamma_{a t m}{ }^{H}$ tends to decrease at a lower rate as the altitude increases. It must be considered that the linear fits relative to the various grazing angles are representative of the data trends only in the altitude intervals were the experimental data were collected. Furthermore, the experimental flight sorties were carried out only in clear weather with similar values of the relevant meteorological parameters measured on the ground (i.e., visibility, relative humidity and temperature). Therefore, it is possible that using these functions beyond the respective altitude intervals and in different weather conditions may not provide reliable predictions of the attenuation coefficient. In order to obtain accurate predictions of the attenuation coefficient variations with altitude, further trials are required to be performed in appropriate meteorological and operational scenarios, including representative weather conditions and wider portions of the TORNADO-IDS/CLDP operational flight envelopes. 


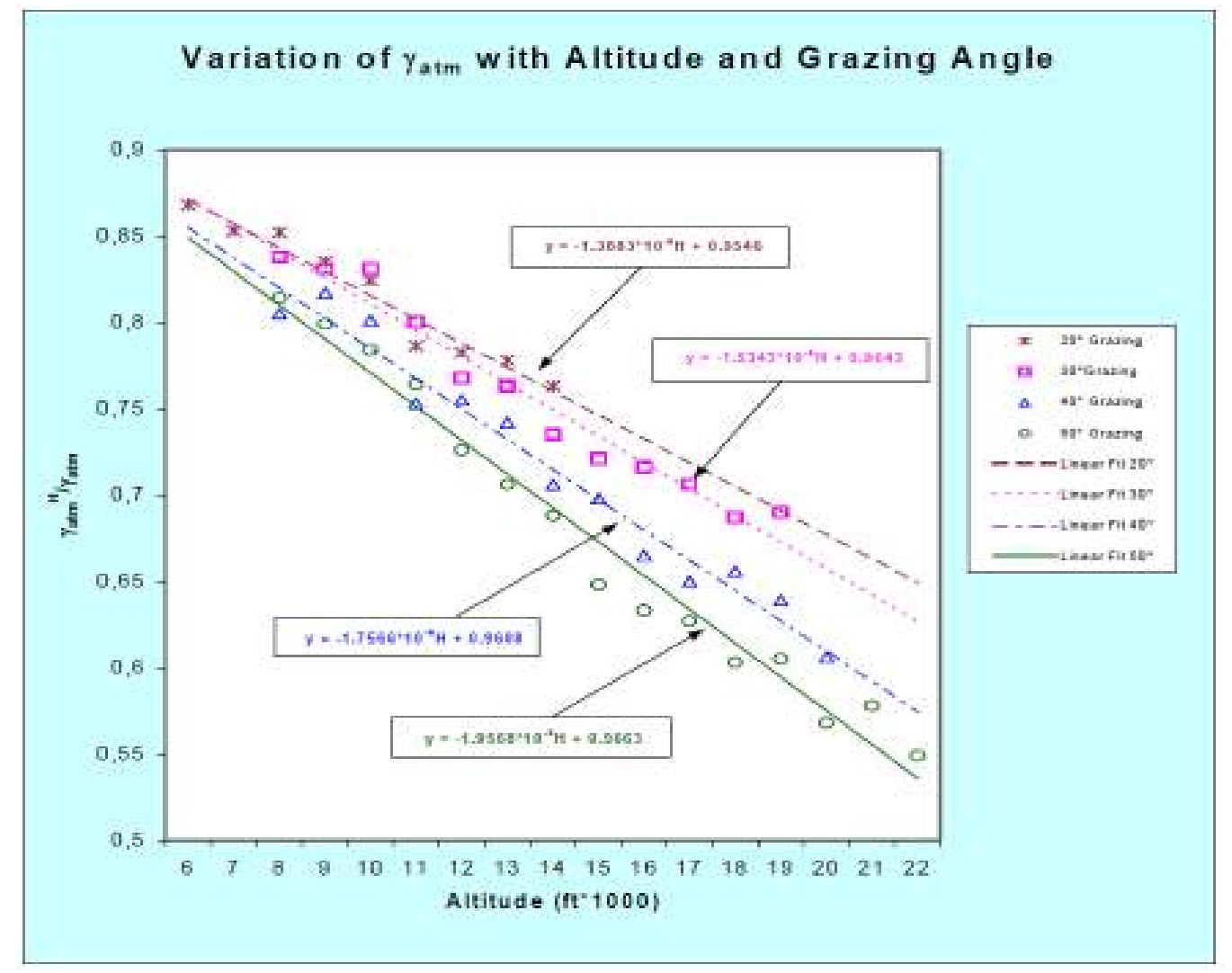

Figure 17. Ratio of the attenuation coefficient to its sea-level value for slant-paths with $20^{\circ}, 30^{\circ}, 40^{\circ}$ and $50^{\circ}$ grazing angles.

\section{Conclusions}

In this paper we have introduced some innovative techniques for laser extinction measurements that represent valid alternatives to traditional LIDAR methods and have a variety of potential applications in manned and unmanned aerospace platforms. Practical implementations can include Satellites, UFV, Parachute/Gliding Vehicles, RSV, or PSI. Various ground and flight test activities were performed in order to assess the proposed techniques and to extend the validity of the mathematical models used for atmospheric extinction calculation, including horizontal propagation paths of several kilometres and determination of extinction gradients over oblique propagation paths (as a function of altitude). In particular, both ground and flight test activities were performed with laser systems operating in the NIR at $\lambda=1064 \mathrm{~nm}$ and $\lambda=1550 \mathrm{~nm}$. These included flight trials performed with a pulsed airborne laser system $(\lambda=1064 \mathrm{~nm})$ installed on a TORNADO-IDS aircraft. During these test activities extinction measurements were performed over horizontal (up to $5.5 \mathrm{~km}$ ) and oblique propagation paths (up to altitudes of $22,000 \mathrm{ft}$ AGL), in a variety of atmospheric conditions. The results of these test activities were very encouraging and the ESLM correction factors/differences presented in this paper have been used extensively by the Italian Air Force and other NATO Defense Forces to evaluate the performance of various aerospace laser systems within the weather and flight-envelope boundaries covered in this research. However, additional ground and flight test activities are required in order to build a Laser Propagation Database (LPD) that would provide additional information about the variation of the relevant atmospheric parameters over extended flight-envelopes and in a wider range of experimental conditions.

\section{Acknowledgments}

The authors would like to thank the Italian Air Force CSV and RSV personnel for supporting the flight test activities. Great tanks go to the NATO Research and Technology Organisation Flight Test Technical Team (FT3) 
for their expert advice and support. Many thanks go to the personnel of SELEX and LOT-ORIEL for their support to the laser test range program.

\section{References}

[1] Weichel H., "Laser Beam Propagation in the Atmosphere." SPIE Optical Engineering Press. Second Printing (1990).

[2] Hudson R.D., [Infrared Systems Engineering]. Wiley \& Sons (1969).

[3] Elder T. and Strong J., "The Infrared Transmission of Atmospheric Windows.” J. Franklin Institute 255 - 189 (1953).

[4] Langer R.M., Signal Corps Report nº DA-36-039-SC-72351 (1957).

[5] Middleton W.E.K., "Vision Through the Atmosphere." University of Toronto Press (1952).

[6] Middleton W.E.K., "Vision Through the Atmosphere." Handbuch der Physik 48. Geophysics 2. Springer, Berlin (1957).

[7] Kneizys F.X., Shuttle E.P., Abreau L.W., Chetwynd J.H., Anderson G.P., Gallery W.O., Selby J.E.A., and Clough S.A., "Users Guide to LOWTRAN 7." Air Force Geophysical Laboratory Report AFGL-TR-88-0177. Hansom AFB (1988).

[8] Holst G.C., [Electro-Optical Imaging System Performance], SPIE Optical Engineering Press. Bellingham, Washington USA (1995).

[9] Gebhardt F.G., "High Power Laser Propagation." Applied Optics - Vol. 15, p. 1479 (1976).

[10] Rodgers C.D., "Inverse Methods for Atmospheric Sounding: Theory and Practice." Atmos. Oceanic Planet. Phys. - Vol. 2 (p. 238). World Science. River Edge, NJ (2000).

[11] Veselovskii I., Kolgotin A., Griaznov V., Müller D., Franke K., and Whiteman D., "Inversion of multiwavelength Raman lidar data for retrieval of bimodal aerosol size distribution." Appl. Optics - Vol. 43, pp. 1180-1195 (2004).

[12] Müller D., Wagner F., Wandinger U., Ansmann A., Wendisch M., Althausen D., and Hoyningen-Huene von W., "Microphysical particle parameters from extinction and backscatter lidar data by inversion with regularization: Experiment." Appl. Optics - Vol. 39, pp. 1879-1892 (2000).

[13] Abshire J.B., Riris H., Allan G.R., Weaver C.J., MAO J., Sun X., Hasselbrack W.E., Kawar R. and Biraud S., "Pulsed airborne lidar measurements of atmospheric $\mathrm{CO}_{2}$ column absorption." Tellus Journal - International Meteorological Institute in Stockholm (2010).

[14] Krainak, M.A, Andrews, A. E., Allan, G. R., Burris, J. F., Riris, H. and co-authors, "Measurements of atmospheric $\mathrm{CO}_{2}$ over a horizontal path using a tunable-diode-laser and erbium-fiber-amplifier at $1572 \mathrm{~nm}$." Proceedings of the Conference on Lasers and Electro-Optics/Quantum Electronics and Laser Science. Technical Digest, Optical Society of America, paper CTuX4, 878-881, ISBN: 1-55752-748-2 (2003).

[15] Riris, H., Abshire, J., Allan, G., Burris, J., Chen, J. and co-authors, "A laser sounder for measuring atmospheric trace gases from space." Proc. SPIE 6750, 67500U, doi:10.1117/12.737607 (2007).

[16] Allan G. R., Riris, H., Abshire J. B., Sun X., Wilson E. and co-authors, "Laser sounder for active remote sensing measurements of $\mathrm{CO}_{2}$ concentrations." Proceedings of the 2008 IEEE Aerospace Conference. IEEE, Big Sky, MT. 1534-1540, doi:10.1109/AERO.2008.4526387 (2008).

[17] Amediek, A., Fix, A. Ehret, G. Caron, J. and Durand, Y., "Airborne lidar reflectance measurements at 1.57 um in support of the A-SCOPE mission for atmospheric $\mathrm{CO}_{2}$." Atmos. Meas. Tech. Discuss. 2, 1487-1536 (2009). 